\title{
Development of Covalent Chitosan-Polyethylenimine Derivatives as Gene Delivery Vehicle: Synthesis, Characterization, and Evaluation
}

\author{
Laura Nicolle ${ }^{1,+}$, Jens Casper ${ }^{2,+}{ }^{\mathbb{D}}$, Melanie Willimann ${ }^{3,+}{ }^{,}$, Céline M. A. Journot ${ }^{1}$, Pascal Detampel ${ }^{2}$ (D), \\ Tomaž Einfalt ${ }^{2}$, Hiu Man Grisch-Chan ${ }^{3}\left(\mathbb{D}\right.$, Beat Thöny ${ }^{3}$, Sandrine Gerber-Lemaire ${ }^{1, *(\mathbb{D})}$ and Jörg Huwyler ${ }^{2, *(\mathbb{D})}$
}

1 Group for Functionalized Biomaterials, Institute of Chemical Sciences and Engineering Ecole Polytechnique Fédérale de Lausanne, EPFL SB ISIC SCI-SB-SG, Station 6, CH-1015 Lausanne, Switzerland; laura.nicolle@epfl.ch (L.N.); celine.journot@epfl.ch (C.M.A.J.)

2 Division of Pharmaceutical Technology, Department of Pharmaceutical Sciences, University of Basel, Klingelbergstrasse 50/70, CH-4056 Basel, Switzerland; jens.casper@unibas.ch (J.C.); pascal.detampel@unibas.ch (P.D.); tomaz.einfalt@unibas.ch (T.E.)

3 Division of Metabolism and Children's Research Center, University Children's Hospital Zürich, CH-8032 Zürich, Switzerland; Melanie.Willimann@kispi.uzh.ch (M.W.);

HiuMan.Grisch@kispi.uzh.ch (H.M.G.-C.); Beat.Thoeny@kispi.uzh.ch (B.T.)

* Correspondence: sandrine.gerber@epfl.ch (S.G.-L.); joerg.huwyler@unibas.ch (J.H.); Tel.: +41-21-693-93-72 (S.G.-L.); +41-61-207-15-13 (J.H.)

check for updates

Citation: Nicolle, L.; Casper, J.; Willimann, M.; Journot, C.M.A.; Detampel, P.; Einfalt, T.; Grisch-Chan, H.M.; Thöny, B.; Gerber-Lemaire, S.; Huwyler, J. Development of Covalent Chitosan-Polyethylenimine

Derivatives as Gene Delivery Vehicle: Synthesis, Characterization, and Evaluation. Int. J. Mol. Sci. 2021, 22, 3828. https://doi.org/10.3390/ ijms22083828

Academic Editors: Iolanda Francolini and Antonella Piozzi

Received: 17 March 2021

Accepted: 1 April 2021

Published: 7 April 2021

Publisher's Note: MDPI stays neutral with regard to jurisdictional claims in published maps and institutional affiliations.

Copyright: (c) 2021 by the authors. Licensee MDPI, Basel, Switzerland. This article is an open access article distributed under the terms and conditions of the Creative Commons Attribution (CC BY) license (https:// creativecommons.org/licenses/by/ $4.0 /)$.
+ These authors contributed equally to this work.

\begin{abstract}
There is an increasing interest in cationic polymers as important constituents of non-viral gene delivery vectors. In the present study, we developed a versatile synthetic route for the production of covalent polymeric conjugates consisting of water-soluble depolymerized chitosan ( $\mathrm{dCS}$; $\mathrm{M}_{\mathrm{W}}$ 6-9 kDa) and low molecular weight polyethylenimine (PEI; $2.5 \mathrm{kDa}$ linear, $1.8 \mathrm{kDa}$ branched). dCSPEI derivatives were evaluated based on their physicochemical properties, including purity, covalent bonding, solubility in aqueous media, ability for DNA condensation, and colloidal stability of the resulting polyplexes. They were complexed with non-integrating DNA vectors coding for reporter genes by simple admixing and assessed in vitro using liver-derived $\mathrm{HuH}-7$ cells for their transfection efficiency and cytotoxicity. Using a rational screening cascade, a lead compound was selected (dCS-Suc-LPEI-14) displaying the best balance of biocompatibility, cytotoxicity, and transfection efficiency. Scale-up and in vivo evaluation in wild-type mice allowed for a direct comparison with a commercially available non-viral delivery vector (in vivo-jetPEI). Hepatic expression of the reporter gene luciferase resulted in liver-specific bioluminescence, upon intrabiliary infusion of the chitosanbased polyplexes, which exceeded the signal of the in vivo jetPEI reference formulation by a factor of 10. We conclude that the novel chitosan-derivative dCS-Suc-LPEI-14 shows promise and potential as an efficient polymeric conjugate for non-viral in vivo gene therapy.
\end{abstract}

Keywords: chitosan; polyethylenimine copolymer; DNA condensation; gene delivery vector

\section{Introduction}

Gene therapy has emerged in the last decades as a powerful strategy for the treatment of acquired and inherited disorders. Various diseases could benefit from it, including cancer and viral infections, cardiovascular diseases, and inherited Mendelian disorders [1,2]. This approach relies on the modification of gene expression by gene replacement, i.e., transfer of exogenous nucleic acids as a therapeutic gene copy, or precise genome editing [3]. Due to their polyanionic nature and their sensitivity to endonucleases, nucleic acids should preferably be delivered to target cells by means of nanocarriers, also called delivery vectors. These delivery vectors are mainly subdivided in two categories: viral and non-viral [4]. Viral delivery vectors display high transfection efficiency in vivo [5,6] but their inherent 
immunogenicity and/or cytotoxicity, and potential genome integration, remain major drawbacks as they may trigger severe adverse immune responses [4]. Non-viral vectors have less limitations for condensation of genetic material as compared to viral delivery vectors [7]. Consequently, the interest in synthetic non-viral vectors for gene delivery as a potentially safer alternative has steadily increased over the past years.

Non-viral vectors often contain cationic polymers or lipids. Upon condensation with polyanionic nucleic acids, they form polyplexes or lipoplexes, respectively [8,9]. Cationic polymers like polyethylenimine (PEI) can efficiently condense nucleic acids into nanometer-sized structures and are therefore often used for gene delivery [10-12]. Two chemical structures of PEI exist, namely branched (BPEI) and linear (LPEI) PEI. Whilst BPEI contains various primary, secondary, and tertiary amines, LPEI displays only secondary amines [11,13]. PEI is known for its high cationic charge density [14] enabling efficient condensation of nucleic acids via electrostatic interactions [10,15-17]. Most importantly, the high availability of amine groups of PEI displays a large buffering potential at physiological $\mathrm{pH}$ [14]. Consequently, PEI is believed to act as a "proton sponge", favoring endosomal escape of the polyplexes [18]. Although still under debate $[13,19,20]$, the "proton sponge" effect remains the main hypothesis to explain the high cytosolic availability and the enhancement of transfection efficiency of PEI-based systems. Therefore, branched PEI structures and high molecular weight derivatives were introduced to increase the charge density [21-24].

Unfortunately, high transfection efficiency of cationic polymers correlates with an increased cytotoxicity. PEI-mediated toxicity is attributed to its high charge density and poor biodegradability [23]. The introduction of shielding polymers, such as polyethylene glycol (PEG), is an approach to reduce cytotoxicity of PEI-based systems [25]. However, shielding of positive charges and overall stabilization through covalent crosslinking exerts the positive effects at the expense of reduced transfection efficiency [26,27]. It is therefore a challenging task to optimize the structure of cationic polymers to find the right balance between charge density/efficacy, cytotoxicity, and in vivo tolerability [24,28-30].

PEI can be combined with chitosan (CS), a cationic polysaccharide obtained by partial deacetylation of chitin [31,32]. CS is composed of repeating $\beta-(1,4)$-2-amino-D-glucose and $\beta$-(1,4)-2-acetamido-D-glucose units that are linked by 1,4- $\beta$-glycosidic bonds. For the past decades, CS has been largely investigated for various medical and industrial applications [33-37] including drug delivery [38,39]. It is known for its biodegradability [40,41], biocompatibility [42], and ability to condense DNA [4,41,43]. However, the low charge density of CS leads to poor transfection efficiency of CS/DNA systems [4]. Another commonly encountered issue is the poor solubility of CS in organic solvents. These limitations can be overcome by conjugating small functional groups or cationic polymers $[4,42,44-47]$ to the amino and hydroxyl groups of glucosamine units.

The aim of the present study was to design, synthesize, and evaluate novel cationic polymers by using CS as a biocompatible, versatile, and biodegradable backbone covalently modified with low molecular weight PEI chains. As building blocks, depolymerized CS (dCS; $\mathrm{M}_{\mathrm{W}}$ 6-9) and low molecular weight PEI chains (2.5 kDa linear, $1.8 \mathrm{kDa}$ branched PEI) were used. Based on our recent work on CS depolymerization [48], we used water-soluble dCS chains for controlled covalent conjugation with PEI chains via a succinyl (Suc) spacer. A screening cascade (Figure 1) was implemented to guide medicinal chemistry efforts by defining physicochemical parameters required for the covalent polymer candidates. Subsequently, covalent polymer candidates were screened in cell culture using the HuH-7 hepatic cell line to optimize transfection efficiency and to minimize cytotoxicity. A lead candidate was identified using this screening approach, further scaled up, and confirmed in mice to have a high transfection efficiency of the liver. 


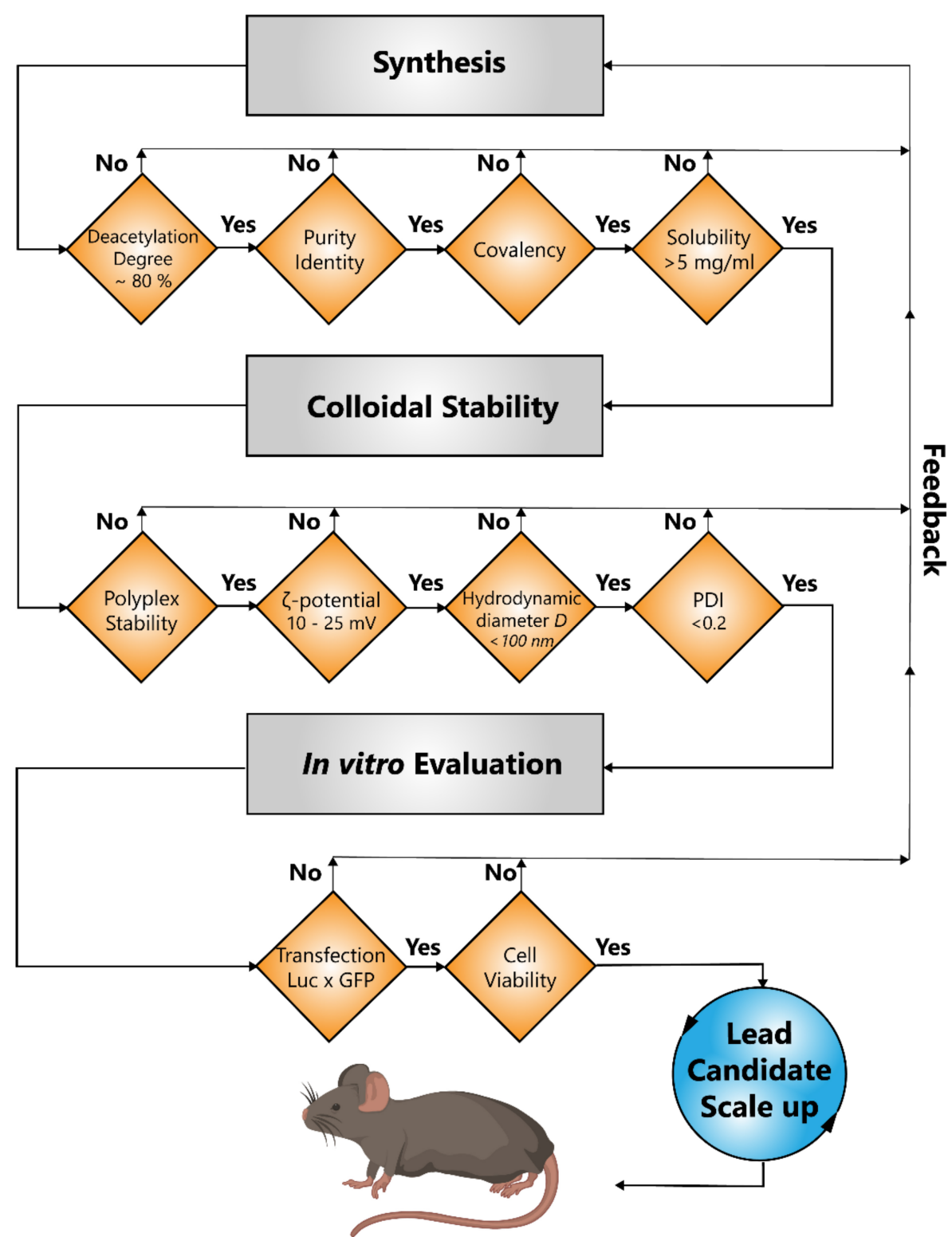

Figure 1. Screening cascade of depolymerized chitosan (dCS)-PEI-based delivery vectors. Identification of a lead candidate was guided by defined chemical properties of the polymer, the indicated physicochemical characteristics of the polyplexes to be met, and biological performance in vitro (i.e., transfection efficiency and cytotoxicity) using the hepatic $\mathrm{HuH}-7$ cell line. Following synthesis, the resulting polymer was chemically identified by ${ }^{1} \mathrm{H}$ NMR and tested for covalent bonding by 2D-diffusion ordered spectroscopy (DOSY) NMR. Only compounds with a solubility of $>5 \mathrm{mg} / \mathrm{mL}$ were selected for further characterization. Colloidal stability was assessed after DNA complexation. In vitro performance was evaluated by using two reporter gene vectors (n.CAGLuc2 and n.CAG.GFP1). The lead candidate is characterized by favorable safety and transfection profiles in vitro allowing for in vivo evaluation of transfection efficiency.

\section{Results}

\subsection{Synthesis and Physicochemical Properties of Covalent dCS-PEI Derivatives}

A synthesis strategy was developed to conjugate dCS as biodegradable backbone with low molecular weight PEI chains to generate efficient and tolerable delivery vectors (Figure 2a). Based on the literature about CS functionalization [49-51], the reactivity of a commercial CS batch (mixture of three CS distributions with $\mathrm{M}_{\mathrm{W}} 479,88$, and $45 \mathrm{kDa}$; determined by gel permeation chromatography (GPC) analysis) was investigated by acti- 
vating its primary amines and then condensing BPEI on it through covalent urea or amide linkages. These attempts were not met with success and pointed out the limited solubility of commercial CS in organic solvents $(<5 \mathrm{mg} / \mathrm{mL})$, thus hampering the development of standardized functionalization procedures. Recently, our group disclosed a microwaveassisted methodology for the fast and controlled depolymerization of CS under acidic conditions, allowing the selection of the polymer's average molecular weight via isolation of the soluble fraction at different $\mathrm{pH}$ values [48]. Following this methodology, depolymerized chitosan (dCS) batches with low polydispersity index and average molecular weight $\left(\mathrm{M}_{\mathrm{W}}\right)$ ranging from 6 to $9 \mathrm{kDa}$ were produced (cf. supporting information S-6 for NMR and GPC data), allowing reliable comparison of the copolymers after functionalization with PEI. Conjugation to BPEI was initially attempted via direct activation of dCS primary amines in the presence of $1,1^{\prime}$-carbonyldiimidazole (CDI) or $\mathrm{N}, \mathrm{N}^{\prime}$-disuccinimidyl carbonate (DSC), followed by condensation with the BPEI units and formation of urea as covalent linkage (Table S1, Scheme S1). For both products, only low grafting degrees (GD) and poor solubility were observed. Therefore, a succinyl (Suc) spacer was introduced for further functionalization via carboxylic acid functionality (Figure 2b).

The resulting intermediate dCS-Suc $\left(\mathrm{GD}_{\mathrm{Suc}}=40-60 \%\right)$ displayed solubility greater than $10 \mathrm{mg} / \mathrm{mL}$ in both aqueous solution and DMSO, enlarging the functionalization possibilities. For both BPEI and LPEI, the optimization of coupling agents, reaction time, and temperature finally led to pure dCS-Suc-BPEI and dCS-Suc-LPEI with 10-15\% GD of the PEI chains (Figure 2b, Table S1 and Table 1). A higher $\mathrm{GD}_{\text {BPEI }}(67 \%)$ was achieved by increasing the proportion of BPEI and the coupling agent (dCS-Suc-BPEI-67, Table 1). Importantly, the homogeneity of dCS-Suc and the final conjugates was improved by centrifugation of the purified derivatives (solution obtained after dialysis), followed by collection and lyophilization of the supernatant. This led to water-soluble final derivatives. Analysis of the precipitates from the centrifugation step revealed also the presence of dCS-Suc-PEI copolymers but with dCS/PEI ratios differing from the values measured in the supernatant. Additionally, those derivatives did not lead to homogeneous solutions in pure distilled water, compromising further biological assessment. These findings pointed out the need to only collect the supernatant obtained after centrifugation for all synthetic intermediates and final derivatives. The detailed characteristics of the polymeric conjugates, which were screened for gene delivery applications, are listed in Table 1.

Anticipating that dCS-Suc-PEI copolymers might have cytotoxic properties due to their residual positive charge after DNA condensation, we considered additional derivatization of the primary alcohols of dCS with linear PEG derivatives (Figure 2c). The end thiol functionality of the PEG chain was selected for further potential stabilization of the polyplexes by chemical cross-linking resulting from disulfide bridge formation. Interestingly, the optimal sequence for this dual functionalization pathway was reversed depending on the PEI structure (linear or branched; Table S2, Scheme S2). In both cases, activation of dCS primary alcohols with CDI, followed by in situ trapping of the imidazolide intermediate with $\mathrm{H}_{2} \mathrm{~N}-\mathrm{PEG}-\mathrm{SH}$, resulted in covalent conjugation of PEG via a carbamate linkage, with a GD ranging from 10 to $36 \%$.

Following their syntheses, the polymeric conjugates were characterized in detail as shown in Table 1, along with the starting polymers in order to compare their chemical composition and solubility. The GD of the polymeric conjugates was calculated for each component and the weight average of Suc, PEI, and PEG units were compared to the total molecular weight $(\mathrm{w} \%)$ of the derivatives. The solubility in neutral to slightly acidic aqueous solutions was a crucial parameter to qualify the conjugates for further evaluation as delivery vectors. Therefore, a minimum solubility threshold of $5 \mathrm{mg} / \mathrm{mL}$ was set to achieve efficient DNA condensation. Apart from dCS-Suc-BPEI-13 (BPEI-functionalized dCS with a grafting degree of $13 \%$; Table 1 ), the solubility value of all polymeric conjugates exceeded $10 \mathrm{mg} / \mathrm{mL}$. Interestingly, dCS and LPEI displayed limited solubility in aqueous solution ( 3 and $5 \mathrm{mg} / \mathrm{mL}$, respectively), whereas their covalent conjugation into dCS-Suc-LPEI11a and dCS-Suc-LPEI-11b resulted in a considerable increase of solubility. Apart from 
dCS-Suc-LPEI-11a, each copolymer detailed in Table 1 was obtained after lyophilization of the supernatant fraction collected from the post-dialysis centrifugation (cf. materials and methods for detailed procedures).

(a)

(2)

CS and dCS

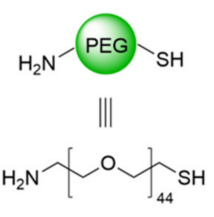

PEG

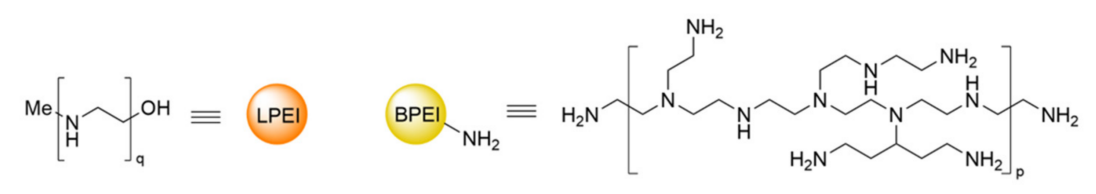
LPEI BPEI

(b)

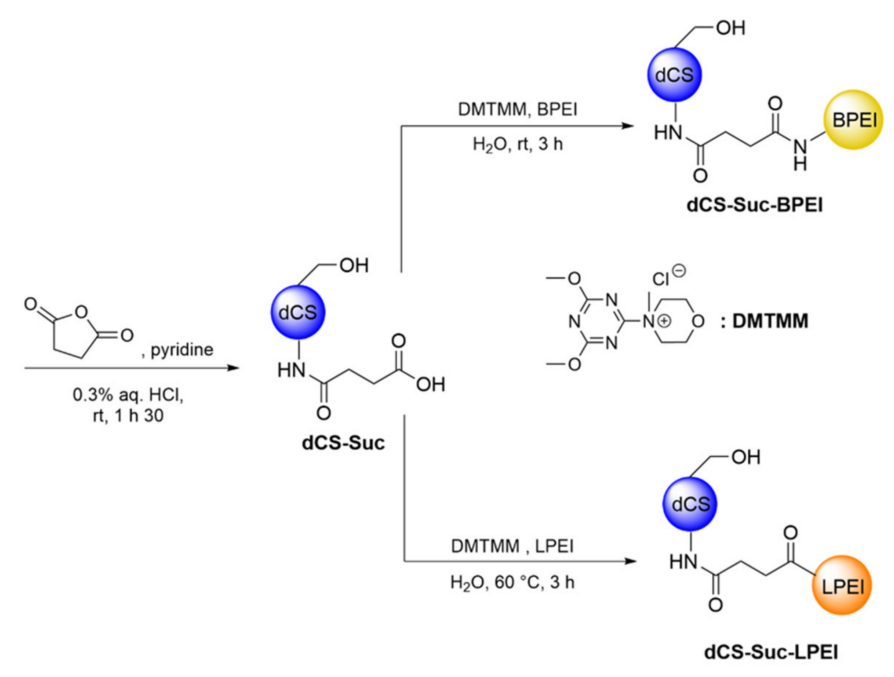

(c)

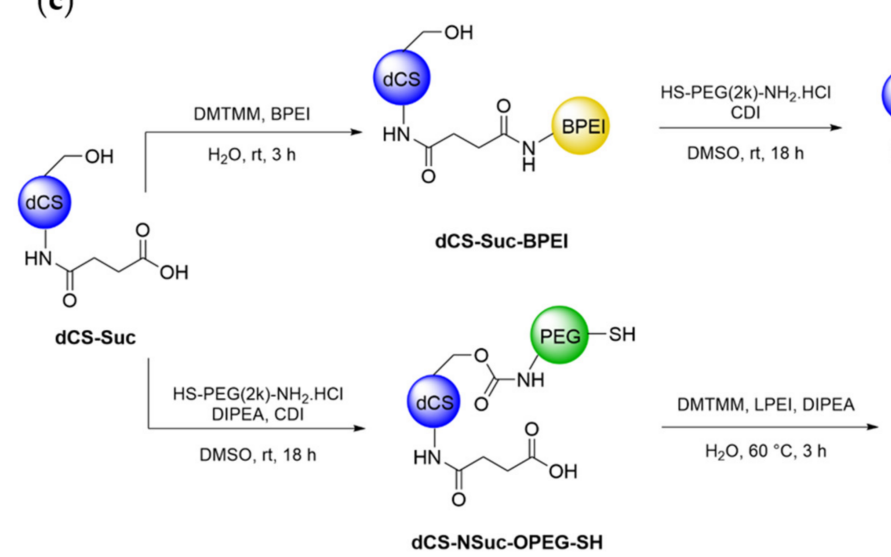

dCS-NSUCBPEI-OPEG-SH

Figure 2. Synthesis of covalent dCS-PEI conjugates. (a) Structures of chitosan (CS, DD $\approx 80 \%$ ), depolymerized chitosan ( $\mathrm{dCS}, \mathrm{DD} \approx 80 \%$ ), polyethylene glycol (PEG, $2 \mathrm{kDa}$ ), and branched (BPEI, $1.8 \mathrm{kDa}$ ) and linear (LPEI, $2.5 \mathrm{kDa}$ ) polyethylenimine. (b) Synthesis of dCS-Suc-BPEI and dCS-SucLPEI using a succinyl linker (Suc) and DMTMM as water-soluble coupling agent. (c) Synthetic pathways for sequential grafting of BPEI, LPEI, and $\mathrm{H}_{2} \mathrm{~N}-\mathrm{PEG}-\mathrm{SH}$ on dCS-Suc. NSuc: Suc linked to amine groups. OPEG: PEG linked to hydroxyl groups. For detailed representation of the PEI conjugation sites to dCS-Suc, see supporting information, Figure S1. 


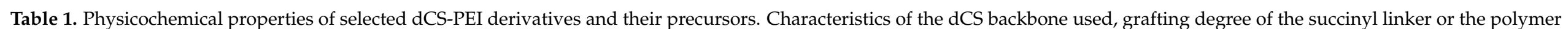

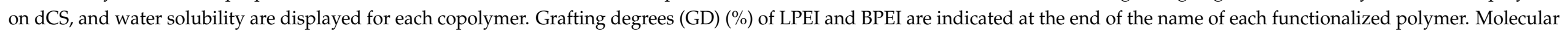
weights of the dCS backbones were estimated by gel permeation chromatography (GPC) and GD were determined by ${ }^{1} \mathrm{H}$ NMR. Nomenclature: cf. Figure 2 .

\begin{tabular}{|c|c|c|c|c|c|c|c|c|c|c|}
\hline \multirow[t]{2}{*}{ Polymer } & \multirow{2}{*}{$\begin{array}{l}\text { Total Molecular } \\
\text { Weight (Da) }\end{array}$} & \multicolumn{2}{|c|}{$\begin{array}{c}\text { Depolymerized Chitosan } \\
\text { (dCS) }\end{array}$} & \multicolumn{2}{|c|}{ Succinate (Suc) } & \multicolumn{2}{|c|}{$\begin{array}{l}\text { Polyethylenimine } \\
\text { (PEI) }\end{array}$} & \multicolumn{2}{|c|}{$\begin{array}{c}\text { Polyethylene Glycol } \\
\text { (PEG) }\end{array}$} & \multirow[t]{2}{*}{$\begin{array}{c}\text { Solubility }^{1} \\
(\mathrm{mg} / \mathrm{mL})\end{array}$} \\
\hline & & Mw (Da) & DD (\%) & GD (\%) & $\mathbf{w} \%$ & GD (\%) & $\mathbf{w} \%$ & GD (\%) & $\mathbf{w} \%$ & \\
\hline \multicolumn{11}{|l|}{ Starting polymer } \\
\hline$-\quad d C S$ & 8300 & 8300 & 79 & - & - & - & - & - & - & 3 \\
\hline - $\quad L P E I$ & 2500 & - & - & - & - & - & - & - & - & 5 \\
\hline - $\quad B P E I$ & 1800 & - & - & - & - & - & - & - & - & $>10$ \\
\hline \multicolumn{11}{|l|}{ BPEI derivatives } \\
\hline - $\quad d C S-S u c-B P E I-13$ & 19,100 & 7800 & 80 & 47 & 12 & 11 & 48 & - & - & $>10$ \\
\hline - $\quad d C S-S u c-B P E I-67$ & 16,900 & 6200 & 80 & 54 & 12 & 13 & 51 & - & - & 7.5 \\
\hline PEG-conjugated BPEI derivatives & 75,300 & 9000 & 80 & 44 & 3 & 67 & 85 & - & - & $>10$ \\
\hline - $\quad$ dCS-NSUcBPEI-OPEG-SH & 43,500 & 7800 & 80 & 47 & 5 & 11 & 21 & 26 & 56 & $>10$ \\
\hline \multicolumn{11}{|l|}{ LPEI derivatives $^{2}$} \\
\hline - $\quad$ dCS-Suc-LPEI-11a & 16,800 & 5700 & 80 & 51 & 10 & 11 & 56 & - & - & $>10$ \\
\hline - $\quad$ dCS-Suc-LPEI-11b & 23,800 & 7800 & 80 & 47 & 10 & 11 & 56 & - & - & $>10$ \\
\hline \multicolumn{11}{|l|}{ PEG-conjugated LPEI derivatives } \\
\hline - $\quad$ dCS-NSUcLPEI-OPEG-SH & 48,300 & 7800 & 85 & 44 & 4 & 22 & 53 & 14 & 27 & $>10$ \\
\hline
\end{tabular}

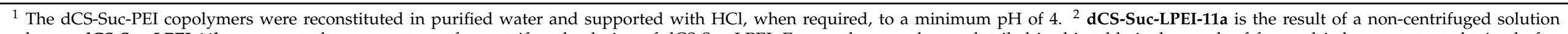

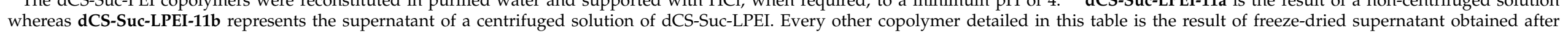
centrifugation (post-dialysis). 


\subsection{NMR Analyses of Covalent dCS-PEI Derivatives}

The polymeric intermediates and final conjugates were characterized by ${ }^{1} \mathrm{H}$ nuclear magnetic resonance (NMR) and 2D-diffusion ordered spectroscopy (2D-DOSY NMR) to confirm the composition, GD, and covalent functionalization for all synthesized derivatives. A representative example of the NMR characterization sequence is given for dCS-SucLPEI-14 (Figure 3). Due to overlapping signals from the dCS backbone and LPEI units, the ${ }^{1} \mathrm{H}$ NMR spectra were recorded in $\mathrm{D}_{2} \mathrm{O}$ (Figure $3 a$ ) and $\mathrm{D}_{2} \mathrm{O} /$ acetic acid- $\mathrm{d}^{4}$ (Figure $3 \mathrm{~b}$ ). The characteristic signal for LPEI $-\mathrm{CH}_{2}$ stands at $2.88 \mathrm{ppm}$ (Figure $3 \mathrm{a}$ ) and $3.52 \mathrm{ppm}$ (Figure $3 b$ ). The determination of the $\mathrm{GD}_{\mathrm{LPEI}}$ was based on the signal of the succinyl spacer (Figure $3 \mathrm{~b}, \mathrm{H}_{8}$ ), which was used as a reference for the integration of the massif of interest (4.13-2.97 ppm) reporting for LPEI - $\mathrm{CH}_{2}$ and glucosamine $\mathrm{H}_{2}$ to $\mathrm{H}_{6}$. Setting the integration of $\mathrm{H}_{8}$ at $2.52 \mathrm{ppm}, \mathrm{GD}_{\mathrm{LPEI}}$ was calculated with the following equation:

$$
G D_{\text {LPEI }}=\frac{H_{\text {total }}-H_{\text {glucosamine }}}{H_{\text {LPEI }}} \times 100
$$

where $H_{\text {total }}$ is the integrated signal $4.13-2.97 \mathrm{ppm}, H_{\text {glucosamine }}$ represents the sum of $\mathrm{H}_{2}, \mathrm{H}_{3}$, $\mathrm{H}_{4}, \mathrm{H}_{5}, \mathrm{H}_{6}$, and $H_{L P E I}$ is the total number of $\mathrm{H}$ in one LPEI chain $(2.5 \mathrm{kDa}$ ) (cf. supporting information S-11 for detailed calculations). In the present case, a $G D_{L P E I}$ of $14 \%$ was calculated. Overall, the alignment of the diffusion constants for all signals of the molecular structures was confirmed for every polymeric conjugate (cf. supporting information S-6 to S-25 for NMR characterization of all synthetic derivatives).

\subsection{In Vitro Performance of DNA Complexed Covalent dCS-PEI Derivatives}

For in vitro assessment, the dCS-PEI derivatives and the polymers used as starting materials (category "Starting polymer" in Table 2) were included in the polyplex-formation analyses. The primary indicator of DNA condensation is evaluated by the amount of polymer required to bind DNA and shield it from external forces. The starting materials dCS and LPEI were observed to form stable complexes at c/p 32 (weight ratio of polymer (c) to nucleic acid (p); c/p ratio) and BPEI at c/p 16 (Table 2). In contrast, dCS-Suc-BPEI and dCS-Suc-LPEI derivatives reached stable polyplexes with DNA at considerably lower $\mathrm{c} / \mathrm{p}$ ratios. Whereas dCS-Suc-BPEI derivatives require the lowest amount of polymer to generate stable polyplexes with values at c/p 0.5 (dCS-Suc-BPEI-13, dCS-Suc-BPEI-67) and $\mathrm{c} / \mathrm{p} 1$ (dCS-Suc-BPEI-11). In comparison, the dCS-Suc-LPEI derivatives formed stable polyplexes at c/p 1 (dCS-Suc-LPEI-11a) and c/p 2 (dCS-Suc-LPEI-11b). Furthermore, additional conjugation of PEG to the linear and branched dCS-Suc-PEI system did not alter the polyplex stability (dCS-NSucLPEI-OPEG-SH and dCS-NSucBPEI-OPEG-SH). The polymeric systems synthesized within this study improved the DNA condensation ability by 8-64-fold compared to starting polymers dCS, LPEI, and BPEI.

To ensure efficient cellular uptake and cellular trafficking of polyplexes, a moderately positive surface potential, small size, and low polydispersity are required [52-55]. The optima for these colloidal properties do not necessarily coincide with the amount of dCSPEI derivatives required to form stable polyplexes. At the abovementioned $\mathrm{c} / \mathrm{p}$ ratios, $\zeta$-potential of polyplexes can be negative or close to neutral, leading to aggregate formation. Therefore, the optimal c/p ratio resulted in small-sized, monodispersed (narrow particle size distribution) particles with slightly positive $\zeta$-potential. Colloidally stable polyplexes were defined by a $\zeta$-potential between 10 and $25 \mathrm{mV}$, a hydrodynamic diameter under $100 \mathrm{~nm}$, and a polydispersity index (PDI) below 0.2. The starting polymers had similar values for colloidal stability at c/p 16 (dCS, LPEI) and 32 (BPEI) as previously observed using agarose gel electrophoresis. The dCS-Suc-LPEI derivatives required the same amounts of polymer to form colloidally stable particles. However, dCS-Suc-BPEI polyplexes required two- (dCS-Suc-BPEI-11 and dCS-Suc-BPEI-67) to eight-fold (dCS-Suc-BPEI-13) higher amounts. Interestingly, additional conjugation of PEG only marginally altered the colloidal stability of the polyplexes. At the corresponding $\mathrm{c} / \mathrm{p}$ ratio of the starting polymers, only LPEI failed the requirements displaying a $\zeta$-potential of $28 \mathrm{mV}$. Interestingly, all LPEI 
and BPEI derivative-based polyplexes demonstrated a surface charge within the requirements. Some polyplexes displayed a lower $\zeta$-potential compared to the corresponding starting polymers (e.g., $16 \mathrm{mV}$, dCS-Suc-BPEI-13), which was further reduced by the conjugation of PEG (13 mV, dCS-NSucBPEI-OPEG-SH). Almost all polyplexes displayed a hydrodynamic diameter under $100 \mathrm{~nm}$ including polyplexes formed by starting polymers (Table 2). The group of dCS-Suc-BPEI-based polyplexes decreased marginally in size compared to BPEI-based polyplexes, whereas dCS-Suc-LPEI derivative-based polyplexes were bigger compared to LPEI-based polyplexes. As expected, the additional conjugation of PEG onto dCS-Suc-BPEI led to bigger polyplexes $(121 \mathrm{~nm})$, whereas dCS-NSucLPEIOPEG-SH-based polyplexes displayed a similar size compared to dCS-Suc-LPEI-based polyplexes. Polyplexes based on starting polymers showed a PDI $<0.2$. In particular, dCS-Suc-LPEI-11b and dCS-NSucLPEI-OPEG-SH showed a homogeneous particle size distribution (PDI < 0.2). In contrast, dCS and most of the dCS-Suc-LPEI-based and dCSSuc-BPEI-based polyplexes displayed values $>0.2$.

The polyplexes were further evaluated by the DNA exclusion assay to determine whether the complexation itself provides protection from external factors. A c/p of 32 for dCS/DNA showed complete shielding of the DNA. Interestingly, polyplexes of LPEI c/p 32 and BPEI c/p 16 showed residual accessibility of DNA resulting in $6 \% \pm 1 \%$ and $5 \% \pm 3 \%$ of unshielded DNA, respectively. However, the other derivative groups with and without conjugated PEG displayed complete DNA encapsulation (Table S3).

We next assessed the transfection efficiency of the delivery vectors using luciferase and GFP encoding nanovector-DNAs using the same polymer/DNA ratio determined as optimal regarding its colloidal stability. To ensure a rapid screening, only $\mathrm{c} / \mathrm{p}$ ratios of polyplexes were tested, which showed optimal colloidal stability. In order to compare luciferase and GFP transfections levels, data were normalized to dCS c/p 32 polyplexes (baseline value, i.e., 1). The transfection efficiency of the starting polymers LPEI and BPEI improved by over 2000- and 3000-fold compared to dCS, respectively (Table 2). Whilst the transfection efficiency was almost the same for dCS-Suc-BPEI-67, dCS-Suc-BPEI-11, and dCS-Suc-BPEI-13-based polyplexes were inferior compared to BPEI-based polyplexes. With regard to dCS-Suc-LPEI derivative-based polyplexes, both derivatives increased the transfection efficiency in comparison to their starting polymers dCS and LPEI. Significant improvement of transfection efficiency was measured for dCS-Suc-LPEI-11b resulting in an over 70,000-fold increase compared to dCS and 34-fold to LPEI, respectively. Unexpectedly, the derivatives conjugated with PEG resulted in a complete loss of transfection.

Lastly, the effect of the polyplexes on cell viability was assessed using the hepatic cell line HuH-7. In the cell viability assay on the one hand, LPEI and BPEI-based polyplexes yielded only $25 \%$ and $43 \%$ viable cells, respectively. On the other hand, the biocompatible and biodegradable dCS polyplexes showed no detrimental effect on cell viability. A significant increase in cell viability resulted from the covalent conjugation of dCS to PEI (min 61\% for dCS-Suc-BPEI-67, max 101\% for dCS-Suc-LPEI-11b). Additional conjugation of PEG had beneficial effects on BPEI-based polyplexes but showed no clear trend for LPEIbased polyplexes.

Considering the different characteristics of polyplexes for colloidal stability, in vitro transfection and tolerability, dCS-Suc-LPEI-11b showed the most favorable properties and was therefore selected as the lead candidate. At that stage, the functionalization of dCS-Suc-PEI conjugates with PEG was shown to require further optimization, since the transfection efficiency was severely reduced and the shielding did not induce beneficial effects on cell viability. 
(a)

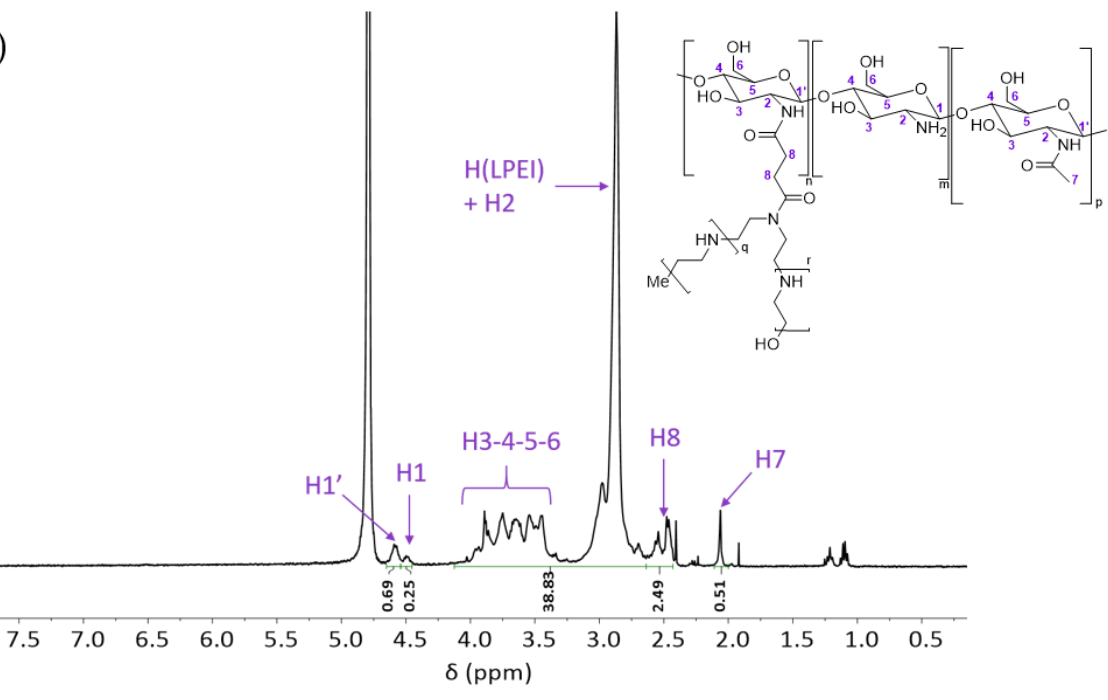

(b)

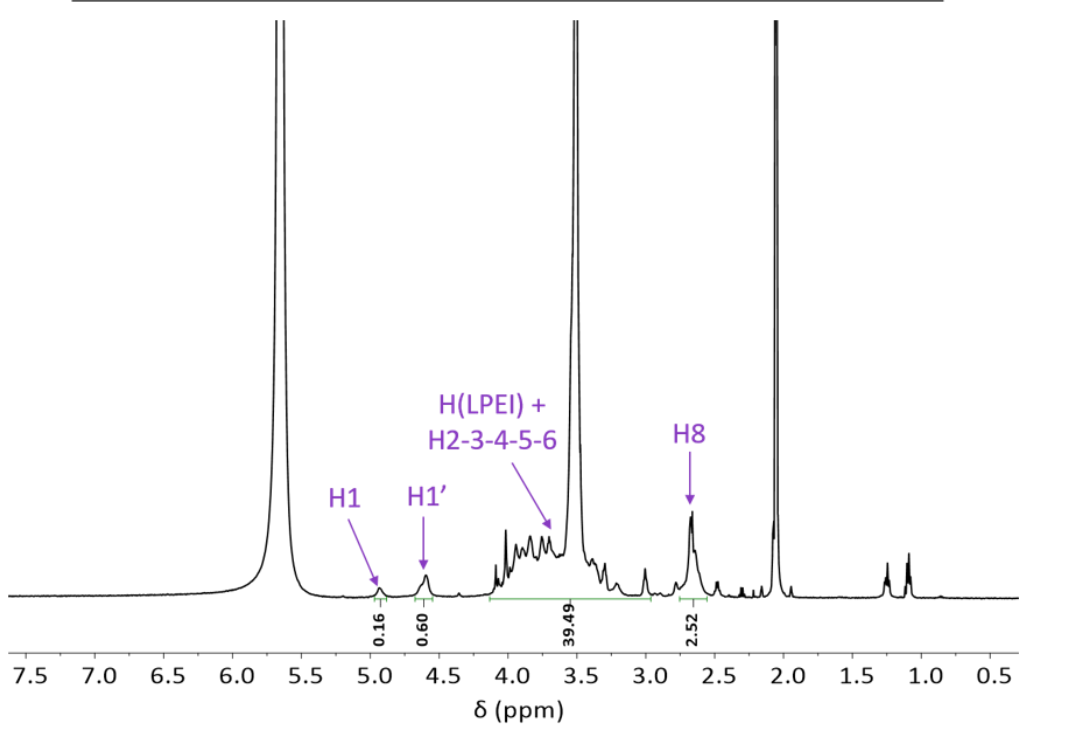

(c)

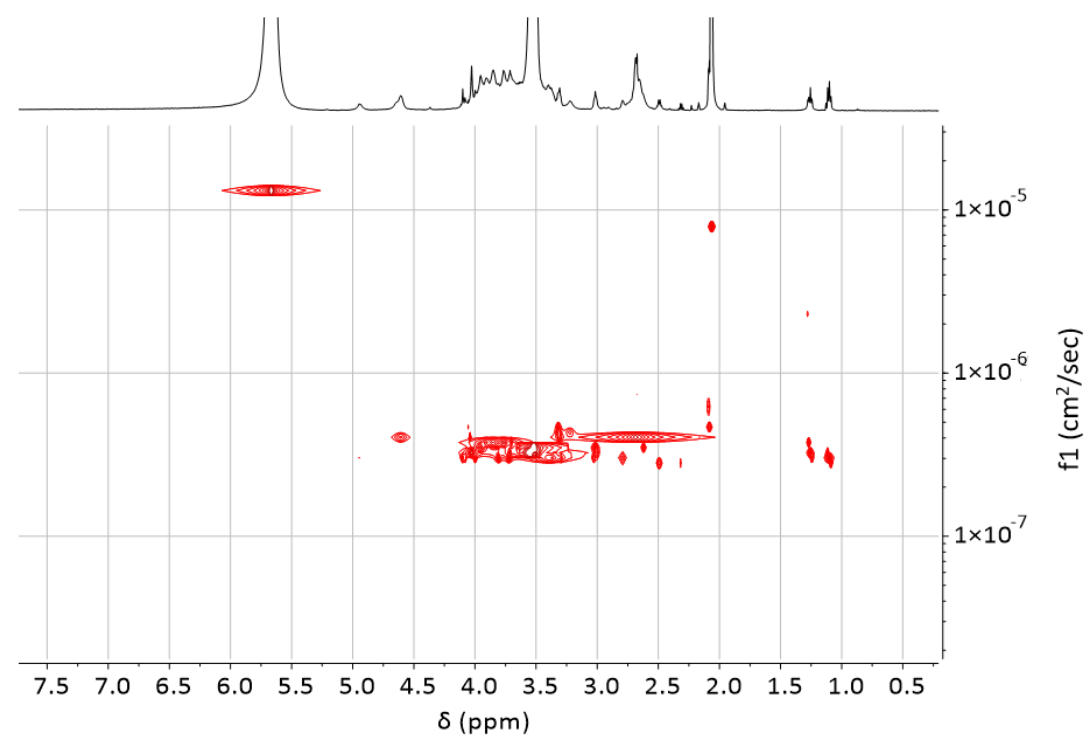

Figure 3. NMR characterization of dCS-Suc-LPEI-14. (a) ${ }^{1} \mathrm{H}$ NMR spectrum in $\mathrm{D}_{2} \mathrm{O}$ and (b) in $\mathrm{D}_{2} \mathrm{O} /$ acetic acid- $\mathrm{d}^{4}$. (c) Determination of the covalent bonding of dCS-Suc-LPEI-14 by 2D-DOSY NMR in $\mathrm{D}_{2} \mathrm{O} /$ acetic acid-d $\mathrm{d}^{4}$. For details on analyses and assignments, cf. Supporting information S-11. 


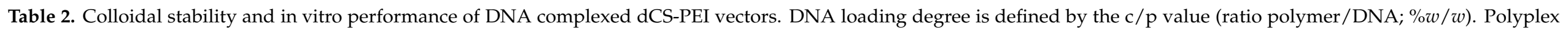

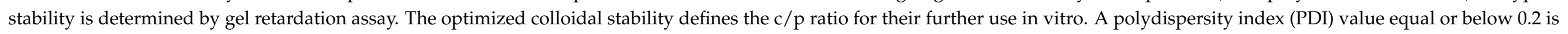

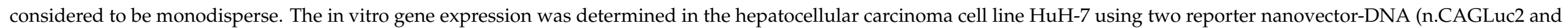

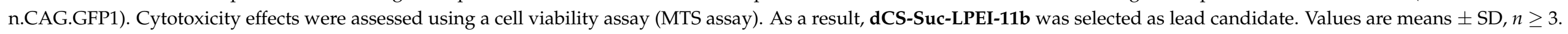
Nomenclature: cf. Figure 2.

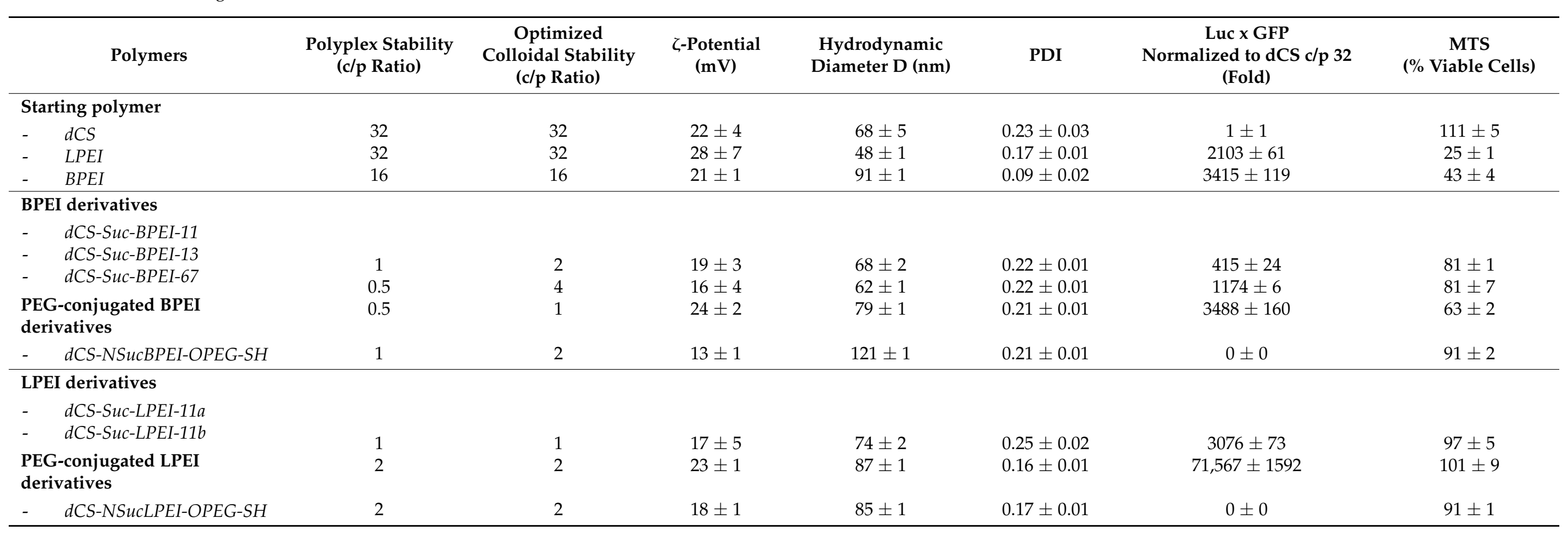




\subsection{Selection of a Lead Compound}

Based on in vitro results (cf. Section 2.3) and following the screening procedure detailed in Figure 1, dCS-Suc-LPEI-11b was identified as a lead compound. This lead candidate did meet all criteria defined by the screening cascade including chemical properties of the copolymer, physicochemical characteristics of the polyplex referred to as colloidal stability (i.e., $\zeta$-potential, hydrodynamic diameter $D$, and PDI), and biological performance in vitro. The stability assay (i.e., an assessment of the extent of nucleic acid complexation by agarose gel electrophoresis) allowed us to determine the amount of copolymer required to successfully condense DNA. The lead candidate was then synthesized on a larger scale $(\approx 900 \mathrm{mg}$ ) to allow for mechanistic studies and in vivo investigations. From here onward, the scaled-up batch of dCS-Suc-LPEI-11b will be referred to as dCS-Suc-LPEI-14 (LPEIfunctionalized dCS with a grafting degree of $14 \%$, Table 1). Furthermore, we assessed the reproducibility of the whole procedure by conducting each reaction on several parallel batches, which were combined after validating their characteristics: in total, four batches of $1 \mathrm{~g}$ were produced for the preparation of dCS-Suc $\left(\mathrm{GD}_{\mathrm{Suc}} 63 \%\right.$, yield $\left.67 \%\right)$ and seven batches of $0.2 \mathrm{~g}$ for dCS-Suc-LPEI-14 (GD LPEI $14 \%$, yield 35\%; cf. Table S4).

\subsection{In Vitro Gene Expression and Cytotoxicity Evaluation of the Lead Candidate}

The lead candidate dCS-Suc-LPEI-14 was further evaluated. Different $\mathrm{c} / \mathrm{p}$ ratios were investigated with focus on transfection efficiency and potential cytotoxic effects. Used methods included confocal microscopy, luciferin conversion, quantitative polymerasechain reaction (qPCR), and flow cytometry to distinguish between apoptosis and necrosis (Figure 4a-d). Transfection using dCS-Suc-LPEI-14-based polyplexes led to an isolated, but strong expression of the fluorescent reporter GFP at c/p 2 as compared to control (i.e., untreated cells), transfection with naked DNA, or dCS c/p 32 (Figure 4a). We observed nonhomogenous distribution of GFP signals, which corresponded with the findings from flow cytometry experiments (see Figure S2) and with previous observations with dCS-Suc-LPEI11b. Depending on the $\mathrm{c} / \mathrm{p}$ ratio, up to $34 \%$ of the cells were transfected. The polyplexes were further evaluated with luciferase-encoding nanovector-DNA as a preliminary test for further in vivo experiments. The luciferase transfection using dCS-Suc-LPEI-14 resulted in $3.2 \times 10^{7} \mathrm{RLU} / \mathrm{mg}$ protein for $\mathrm{c} / \mathrm{p} 2$ and only marginally increased with higher amounts of polymer (c/p 8; Figure $4 \mathrm{~b})$. A similar observation was made when luciferase copy numbers were determined by qPCR (Figure 4c). The luciferase copy numbers increased by almost three orders of magnitude when transfected with polyplexes of $\mathrm{c} / \mathrm{p} 0.5$ to $\mathrm{c} / \mathrm{p} 2$ and plateaued at $\mathrm{c} / \mathrm{p} 2$. To determine the number of apoptotic and necrotic cells, 7-AAD (7-aminoactinomycin D) and Annexin V double-labeling was conducted and analyzed by flow cytometry (Figure 4d). Compared to cells treated with DNA only, dCS-Suc-LPEI14 showed marginal elevation of 7-AAD and Annexin V positive cells. The in-depth characterization of the scaled-up lead candidate dCS-Suc-LPEI-14 confirmed the results from the screening experiments and qualified this derivative for testing in wild-type mice.

\subsection{In Vivo Assessment of the Lead Candidate}

The in vivo transfection efficacy of dCS-Suc-LPEI-14 complexed with luciferase encoding nanovector-DNA was assessed in wild-type mice. Complexes of dCS-Suc-LPEI-14 at a c/p ratio of 2.0 were formed using $1 \mu \mathrm{g}$ up to $50 \mu \mathrm{g}$ of nanovector-DNA (n.P3Luc1) expressing the luciferase from the liver-specific promoter P3. For comparison, we used the commercially available non-viral delivery vector in vivo-jetPEI [56] and encapsulated $1 \mu \mathrm{g}$ n.P3Luc1 at c/p 1.1 according to the manufacturer's protocol. The polyplexes were administered intrabiliary as these derivatives are not designed to target the liver upon systemic injection. The systemic administration was investigated in a pilot experiment showing that intravenous injection of the dCS-Suc-LPEI-14-based polyplexes did not result in any luciferase expression up to day three $(10 \mu \mathrm{g}$ and $50 \mu \mathrm{g}$ nanovector-DNA injected intravenous, data not shown). Therefore, the polyplexes containing $1 \mu \mathrm{g}$ nanovector-DNA (and $5 \mu \mathrm{g}$ and $10 \mu \mathrm{g}$ nanovector-DNA, data not shown) were administered by retrograde in- 
fusion through the gallbladder for liver cell transfection. In vivo bioluminescence imaging (IVIS) was followed at day one, two, and three post infusion (Figure 5a,b). Mice injected with in vivo-jetPEI showed an average luciferase expression of $6.4 \times 10^{6}$ photons / s over a period of three days, whereas mice injected with dCS-Suc-LPEI-14 polyplexes showed an enhanced luciferase signal of $7.9 \times 10^{7}$ photons/s. Thus, the use of dCS-Suc-LPEI-14 polyplexes exceeded the luciferase expression by more than ten-fold compared to in vivo-jetPEI (Figure 5a). Furthermore, luciferase expression was confined to be specific to the liver based on in vivo imaging system (IVIS) (Figure 5b). Subsequently the same polyplexes were tested upon pre-administration of the anti-inflammatory drug dexamethasone [57] in an effort to suppress liver toxicity and jaundice in mice. The dexamethasone treated mice exhibited a slight increase of luciferase expression compared to non-treated ones, and again a higher expression for the dCS-Suc-LPEI-14 polyplexes compared to the in vivo-jetPEI control was observed, i.e., $1.1 \times 10^{8} \mathrm{p} / \mathrm{s}$ versus $2.3 \times 10^{7} \mathrm{p} / \mathrm{s}$, respectively. Levels of standard liver markers were determined in the serum of mice upon euthanization at day 3. Bilirubin and ALT levels could be reduced by dexamethasone pretreatment while ALP levels were not significantly affected.

(a)
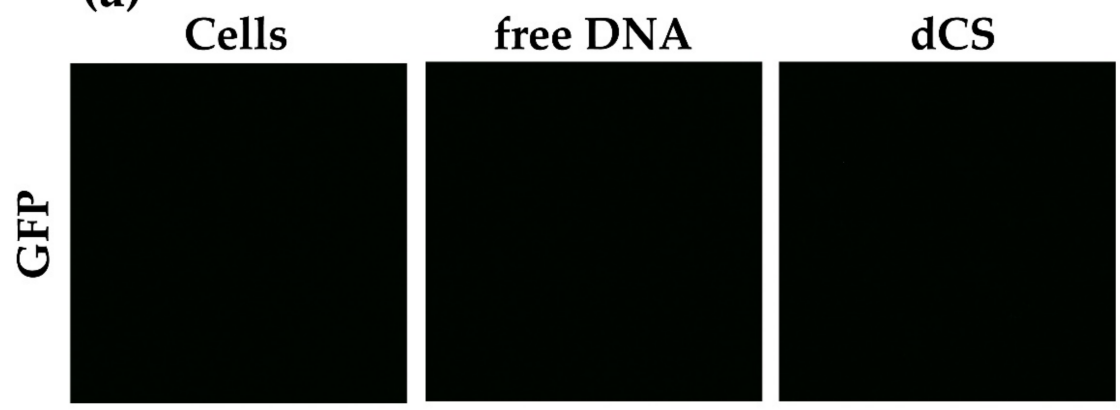

dCS-Suc-LPEI-14
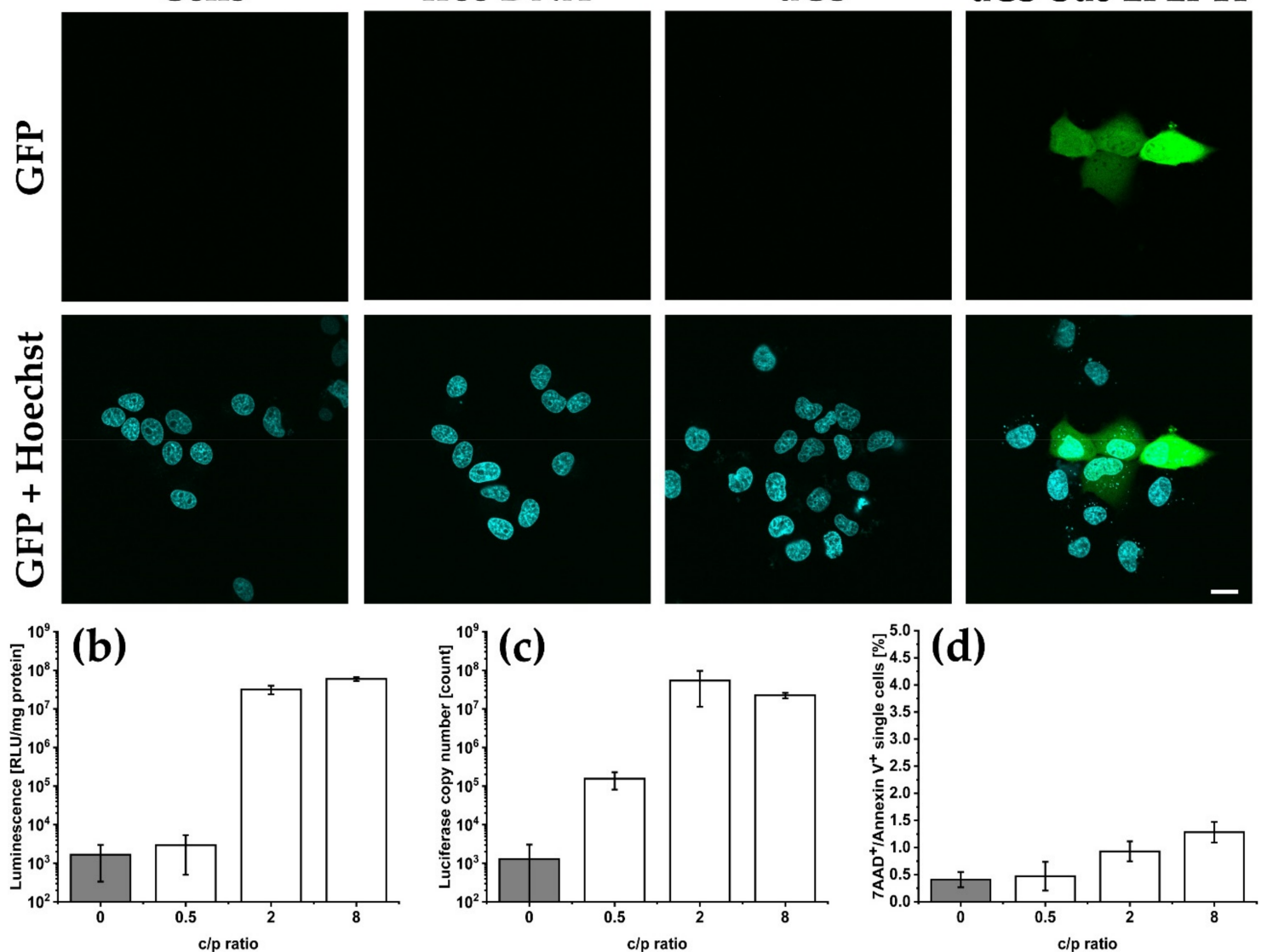

Figure 4. In vitro gene expression and toxicity pattern of the lead candidate. Experiments were conducted using two reporter gene nanovector-DNA (n.CAGLuc2 and n.CAG.GFP1). (a) Left Panel: Untreated control cells. Nuclei were stained with Hoechst 33,342 (Blue). Middle Panels: Expression of GFP in HuH-7 cells $48 \mathrm{~h}$ after transfection with free DNA and dCS. Right panel: Expression of GFP in HuH-7 cells $48 \mathrm{~h}$ after transfection with lead candidate dCS-Suc-LPEI-14. Scale bar: $20 \mu \mathrm{m}$. (b-d) In vitro evaluation of HuH-7 cells at c/p ratios 0 (free DNA), 0.5, 2, and 8: (b) quantitative assessment of luciferase expression as a function of $\mathrm{c} / \mathrm{p}$ ratios. Gene expression of luciferase is based on luciferin conversion. (c) Delivery of luciferase reporter genes as determined by quantitative polymerase-chain reaction (qPCR). (d) Evaluation of late apoptotic and necrotic cells $48 \mathrm{~h}$ after incubation with dCS-Suc-LPEI-14. Values are means $\pm \mathrm{SD}, n \geq 3$. 
(a)

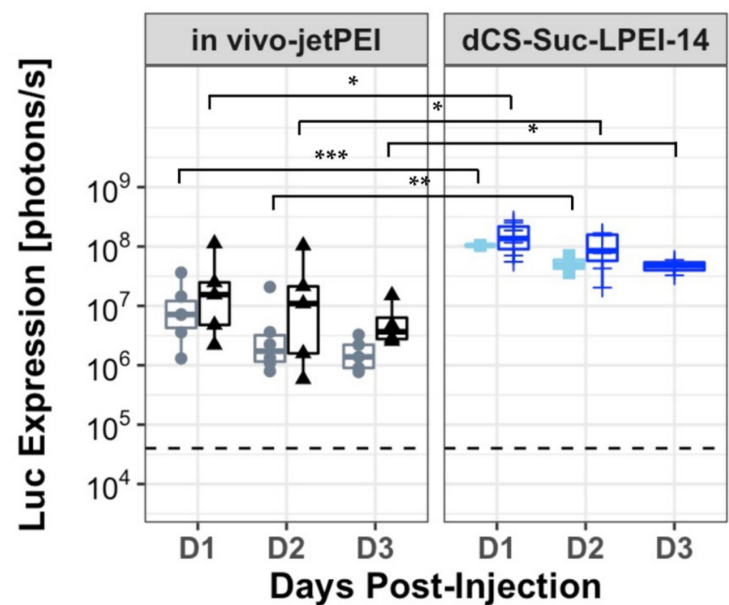

in vivo-jetPEI

in vivo-jetPEI + dexamethasone (b)

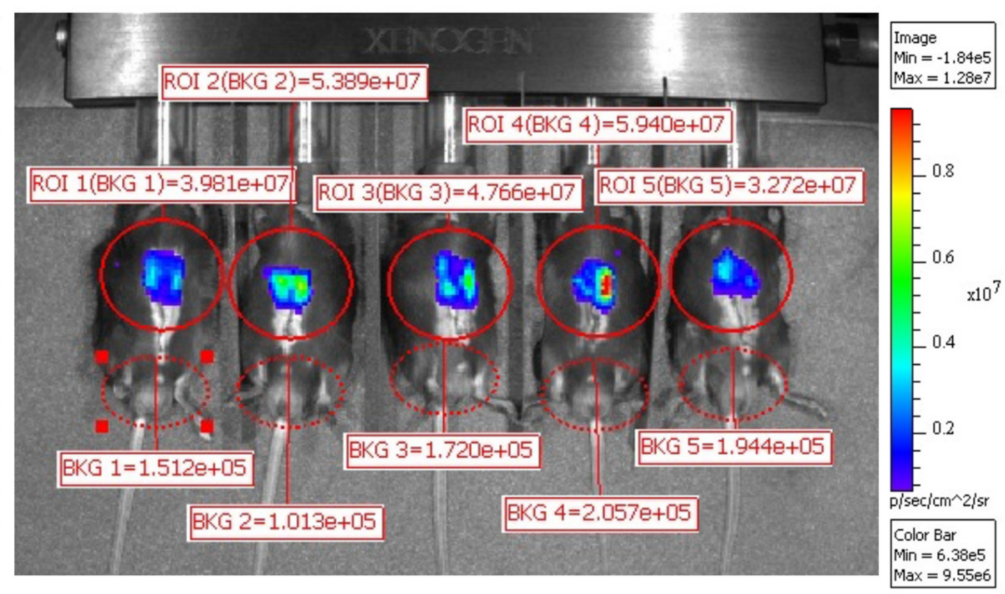

(c)

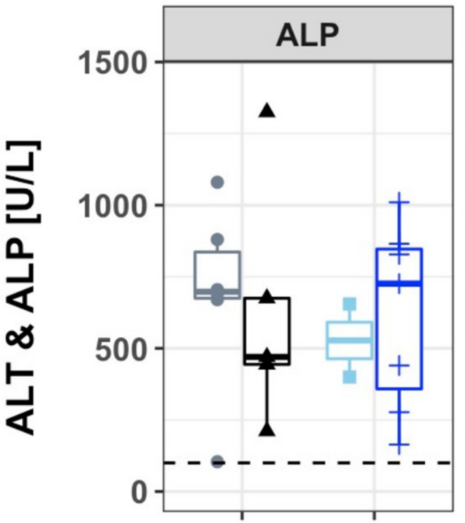

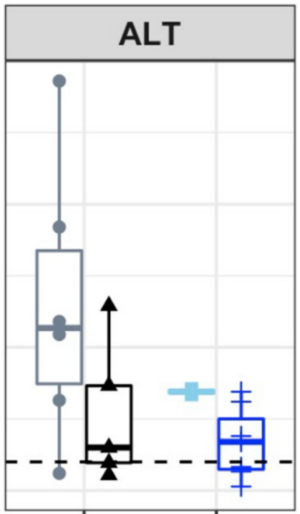

(d)
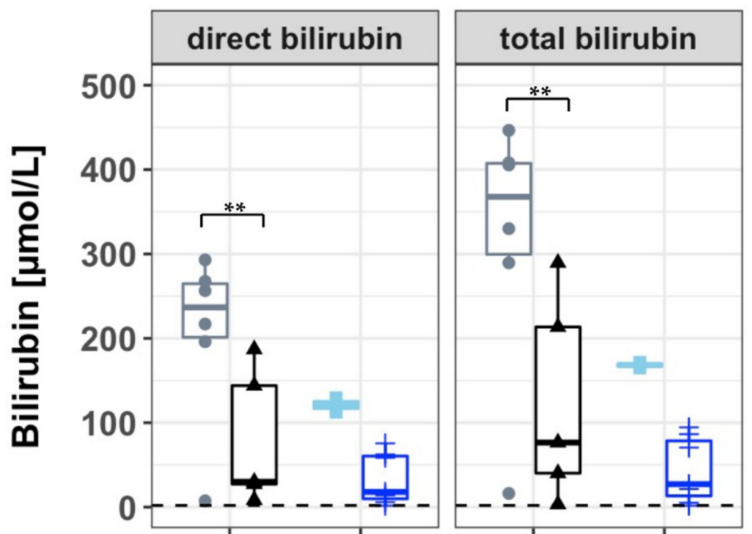

Figure 5. In vivo assessment of dCS-Suc-LPEI-14 upon retrograde intrabiliary infusion into wild-type mice. (a) Luciferase expression levels up to three days post retrograde intrabiliary infusion of $1 \mu \mathrm{g}$ nanovector-DNA encapsulated with a $\mathrm{c} / \mathrm{p}$ ratio of 2 (dCS-Suc-LPEI-14) and 1.1 (in vivo-jetPEI). Animals were pretreated without $(n=6)$ or with dexamethasone $(n=5)$ for in vivo-jetPEI, and without $(n=2)$ or with dexamethasone $(n=5)$ for dCS-Suc-LPEI-14. Note that mice injected without dexamethasone showed signs of jaundice and severe cases had to be euthanized (and were therefore not screened for IVIS). (b) Detection of liver-associated bioluminescence in mice three days post intrabiliary infusion $(1 \mu \mathrm{g}$ DNA/dCS-Suc-LPEI-14 + dexamethasone). (c,d) Serum markers for hepatotoxicity, including alkaline phosphatase (ALP), alanine transaminase (ALT), total bilirubin, and direct bilirubin. Statistical differences by Student's two tailed $t$-test: ${ }^{*}=p<0.05,{ }^{* *}=p<0.01$, ${ }^{* * *}=p<0.001$. Dashed line: background $=$ untreated mice. Values are means $\pm \mathrm{SD}, n \geq 3$.

\section{Discussion}

In the present study, CS was used as a backbone for the design of biodegradable and biocompatible PEI derivatives. Functionalization was achieved by covalent modification of amino and hydroxyl groups of CS units. To overcome the poor water solubility of CS, we used a small molecular weight depolymerized CS recently introduced [48]. Furthermore, the depolymerization of CS led to a homogenous polymer size distribution of the resulting low molecular weight dCS preparations. This was shown to be essential for reproducible functionalization and further processing since copolymers isolated from conjugation with the commercial CS contained agglomerates of molecules with highly variable molecular weights. Using water-soluble dCS as a starting polymer allowed us to develop synthetic 
pathways for the sequential coupling of PEI and PEG chains. The introduction of a succinyl spacer was a prerequisite to use an amide bond formation coupling agent like DMTMM (4-(4,6-dimethoxy-1,3,5-triazin-2-yl)-4-methyl-morpholinium chloride). Due to the high water-solubility of DMTMM, BPEI and LPEI covalent grafting to dCS-Suc could be easily carried out in water with great reproducibility (Figure 2 and Table S4). This synthetic strategy is in contrast to usual ones, where the EDC/NHS coupling agent system is more frequently used to form amide bonds [58]. However, in our case DMTMM led to better and higher grafting degree than EDC/NHS (Table S1). In order to improve the homogeneity and purity of the final conjugates, a centrifugation step had to be introduced after purification by dialysis to remove precipitated polymer aggregates. The impact of this additional treatment on the properties of the copolymers was assessed by comparing dCS-Suc-LPEI11a (not separated by centrifugation) and dCS-Suc-LPEI-11b (separated by centrifugation) as shown by a decrease in PDI by $35 \%$ and the significant differences with respect to their in vitro performance (Table 2).

${ }^{1} \mathrm{H}$ and 2D-DOSY NMR spectroscopies played a central role in the characterization of dCS-based conjugates, allowing not only for the determination of their molecular structure (i.e., composition and grafting degree) but also for the confirmation of the covalent conjugation of all polymeric components (Figure 2). In the present study, we first characterized the different systems by ${ }^{1} \mathrm{H}$ NMR analysis in up to two solvents (pure $\mathrm{D}_{2} \mathrm{O}$ and $\mathrm{D}_{2} \mathrm{O}$ /acetic acid- $\mathrm{d}^{4}$ ), and then ensured their covalent bonding by subjecting them to 2D-DOSY NMR experiments. Confirmation of covalent bonding is of high importance since the assembly of polymers through non-covalent interactions can lead to stable structures resistant to purification by dialysis. Several CS-PEI based systems were already developed for gene delivery in the past 20 years, but their characterization was focused on GPC, FTIR, and ${ }^{1} \mathrm{H}$ $\mathrm{NMR}$, lacking interpretation for covalent bonding [59-61]. In particular, ${ }^{1} \mathrm{H}$ NMR spectra of polymer aggregates may only slightly differ from their covalent analogues and GPC analysis is insufficient since branched polymers cannot be identified by this technique. We believe that the NMR sequence introduced here is crucial to distinguish between covalent and non-covalent assemblies. This methodology can be applied to a large variety of multicomponent copolymers, giving important insight into their molecular structure in relation with their stability and degradation profile in the physiological environment.

As a result of the synthetic chemical effort (Figure 2), six promising candidates could be selected for screening in cell culture models (Tables 1 and 2). All candidates were subjected to an evaluation procedure. To efficiently and rapidly progress from newly synthesized copolymers to a lead candidate, we introduced a rational step-by-step screening approach defining key parameters of different complexities (Figure 1). This includes quality measures for the chemical synthesis, information on colloidal stability, and an in vitro evaluation with respect to transfection efficiency and cytotoxicity. By this screening process, we could eliminate polymeric carriers that displayed unfavorable properties while focusing on candidates with favorable properties for in vivo gene delivery. We could identify two key parameters, which were indispensable for polyplex characterization and performance evaluation, namely colloidal stability and the combined transfection value Luc $\times$ GFP normalized to dCS c/p 32. The colloidal stability combines key parameters of the polyplex, including polyplex stability, $\zeta$-potential, hydrodynamic diameter, and PDI. The resulting value displays an optimized copolymer/DNA ratio that reflects the lowest amount of derivative necessary to have favorable polyplex characteristics, which is of importance since excessive copolymer amounts are the main source for cytotoxic effects. The merged transfection value Luc $\times$ GFP gives a complementary view on transfection efficiency by combining two reporter gene systems to assess on how numerous and how efficient transgenic DNA is delivered to cells. In general, we observed that BPEI derivatives were only effective at higher copolymer/DNA ratios, which is however associated with pronounced cytotoxic effects (data not shown). The toxic effects exerted by the copolymer are linked to the charge density, which is higher for BPEI than for LPEI derivatives [21]. Hence, shielding the charge with PEG moieties has been described as a promising strat- 
egy [25-27]. However, the conjugation of PEG to our systems led to significant reduction of DNA complexation as well as transfection properties. In contrast, other groups were successful in obtaining effective transfection with similar delivery vectors conjugated to PEG $[50,62,63]$. This might be due to several reasons such as steric hindrance of different PEG moieties with varying GD that can hamper proper DNA condensation.

The polymeric delivery vector screening provided a first indication of the superior transfection performance of the selected lead candidate, i.e., dCS-Suc-LPEI-14. Indeed, follow-up experiments with the scaled-up lead candidate revealed an excellent match between in vitro performance and transfection capacity in vivo. In addition, dCS-SucLPEI-14 showed a good balance between transfection efficiency and cytotoxicity (Figure 4). It should be noted that although the cell viability was part of our screening in cell culture models, this parameter has a limited predictive value towards in vivo toxicity affecting the whole organism. Nevertheless, it facilitates a universal approach that can be easily adapted and applied to similar delivery vectors, enabling the possibility to identify promising lead candidates.

Subsequent to the in vitro evaluation, the lead candidate dCS-Suc-LPEI-14 was tested in vivo to confirm the validity of our approach. For the experiments in mice, the commercial transfection reagent in vivo-jetPEI was used as a reference. Furthermore, the experiments were carried out with and without dexamethasone pretreatment $[64,65]$ to suppress proinflammatory processes as we observed liver toxicity as indicated by serum markers and jaundice. Dexamethasone premedication is a standard procedure in clinical trials with test medications such as lipid-based delivery systems where adverse immune events or infusion-related reactions have to be avoided [66]. Indeed, pretreatment with dexamethasone was clearly beneficial with respect to a reduction of ALT and both bilirubin markers but had no statistically significant impact on transgene expression (Figure $5 c, d$ ). Our non-integrating nanovector-DNA, under the control of a liver-specific P3 promoter [67-69] and coding for luciferase, was administered by retrograde intrabiliary infusion. This is an established and efficient way to deliver polymeric delivery vectors to the liver in rodents [70], and is in contrast to a systemic administration [70,71]. Direct intrabiliary infusion allows substantial reduction of the amounts of DNA and polyplexes required. In these experiments only $1 \mu \mathrm{g}$ nanovector-DNA was administered.

Intrabiliary infusion of dCS-Suc-LPEI-14 polyplexes resulted in a luciferase transgene expression that was 10-fold higher as compared to in vivo-jetPEI. In addition, our dCSPEI derivative showed reduced liver toxicity as compared to in vivo-jetPEI. We conclude from this successful proof-of-concept in vivo experiment that covalent combination of $\mathrm{dCS}$ and PEI, as realized in the lead compound dCS-Suc-LPEI-14, is a promising gene delivery strategy. It combines colloidal stability with nucleic acid condensation ability, biocompatibility, and high transfection efficiency in vitro and in vivo.

\section{Materials and Methods}

\subsection{Materials and Cell Cultures}

Reagents and solvents were purchased from commercial sources (Alfa Aesar, Acros, Fluka, Roth, Polysciences Inc., Sigma Aldrich, TCI, ABCR) and were used without further purification unless otherwise stated. In particular, CS was obtained from TCI (5-20 $\mathrm{mPa} \cdot \mathrm{s}$, $0.5 \%$ in $0.5 \%$ acetic acid at $20{ }^{\circ} \mathrm{C}$; DD: $80 \%$; mixture of three distributions with $\mathrm{Mw} 478,900$, 88,410 and $44,800 \mathrm{Da}$ ). BPEI was obtained from ABCR (purity $>99.9 \%$; $1800 \mathrm{Da}$ ) and LPEI was obtained from Polysciences Inc. (2500 Da). HCl.NH 2 -PEG-SH (2000 Da) was obtained from Sigma Aldrich. Centrifugations were performed in an Allegra X-30R Centrifuge (Swinging-bucket rotor, $4700 \mathrm{rpm}$, Beckman Coulter). Dialysis purifications were performed against distilled water at rt unless stated otherwise. Three types of dialysis membranes were used: MWCO $14 \mathrm{kDa}$ (Roth, Membra Cell, regenerated cellulose (RC), dry packaged, treated with glycerine), MWCO $3.5 \mathrm{kDa}$ (Spectra/Por ${ }^{\circledR} 3 \mathrm{RC}$, dry packaged, glycerine-free), and MWCO $7 \mathrm{kDa}$ (Zellu Trans 6-8 kDa, RC, dry packaged). Average time 
of dialysis was set to 3 days with water being renewed 3 times per day. Samples were lyophilized in a VaCo 5 Zirbus technology freeze-dryer $\left(0.3 \mathrm{mbar},-80^{\circ} \mathrm{C}\right)$.

Nanovector-DNA were purchased from Nature Technology Corporation (Lincoln, NE, USA). Nanovector-DNA n.P3Luc1 (2951 bp) and n.CAGLuc2 (5700 bp) encode both the firefly luciferase transgene driven by a synthetic liver specific promoter $\mathrm{P} 3[67,68]$ and the ubiquitously expressing cytomegalovirus (CMV) enhancer fused to the chicken beta-actin (CAG) promoter, respectively. Nanovector-DNA n.CAG.GFP1 (5200 bp) consists of the CAG promoter and the green florescent protein (GFP) as the reporter transgene.

HuH-7 cells were obtained from RIKEN Cell Bank (Ibaraki, Japan) and cultured at $37{ }^{\circ} \mathrm{C}$ with $5 \% \mathrm{CO}_{2}$ and saturated humidity. Cells were kept in Dulbecco's modified Eagle's medium (DMEM) high glucose $(4500 \mathrm{mg} / \mathrm{L})$ and additionally supplemented with $10 \%$ fetal calf serum FCS and $1 \%$ penicillin $(10,000 \mathrm{IU} / \mathrm{mL})$-streptomycin $(10,000 \mu \mathrm{g} / \mathrm{mL})$. Subculturing was performed when cells reached $70 \%$ confluency.

\subsection{Polymers Analytics}

${ }^{1} \mathrm{H}$ NMR and 2D-DOSY NMR spectra were recorded at rt on Bruker 400 Ultrashield $^{\mathrm{TM}}$ Plus and Bruker Avance III HD-600 (respectively 400 and $600 \mathrm{MHz}$, Bruker, Billerica, MA, USA). Spectra were analyzed using Mestre Nova software. Chemical shifts $(\delta)$ were reported in parts per million ( $\mathrm{ppm}$ ) relative to residual solvent peaks rounded to the nearest $0.01 \mathrm{ppm}$ (ref: $\mathrm{CD}_{3} \mathrm{COOD} 2.05 \mathrm{ppm}$ and $\mathrm{D}_{2} \mathrm{O} 4.79 \mathrm{ppm}$ ). Peak multiplicities were indicated as follows: $\mathrm{s}$ (singlet), $\mathrm{d}$ (doublet), $\mathrm{t}$ (triplet), $\mathrm{m}$ (multiplet), and br (broad). All integrations were performed per unit of CS. For infrared spectroscopy data, a Perkin Elmer Frontier FTIR system was used with a QUEST ATR Accessory (diamond Ext Range Accy Frontier). GPC analyses were recorded on two different setups: (1): PL-GPC 50 integrated GPC/SEC system (Agilent) equipped with a refractive index detector, a PSS NOVEMA MAX columns set $(1 \times$ guard column, $10 \mu \mathrm{m} ; 2 \times$ analytical columns $1000 \AA, 10 \mu \mathrm{m} ; 1 \times$ analytical column $30 \AA, 10 \mu \mathrm{m}$ ), using $0.3 \mathrm{M}$ aqueous acetic acid and $0.2 \mathrm{M}$ aqueous sodium acetate as eluents. Samples of CS and dCS (2 mg each) were dissolved overnight in $1.5 \mathrm{~mL}$ of mobile phase. The solutions were filtered through a sterile $0.22 \mu \mathrm{m}$ PTFE filter followed by injection $(100 \mu \mathrm{L})$. Flow rate of analysis: $1 \mathrm{~mL} / \mathrm{min}$ at $40{ }^{\circ} \mathrm{C}$. (2): 1260 Infinity II Agilent GPC/SEC system equipped with a Wyatt triple detection setup: multi-angle light scattering (MALS), viscometer, and refractive index detector (DAWN8). Samples were separated using a guard column (OHpak SB-G 6B, $6 \times 50 \mathrm{~mm}$ ) and a mixed-gel column (OHpak SB-806M HQ, $8 \times 300 \mathrm{~mm})$. Samples of $10 \mathrm{mg}$ were dissolved for $1 \mathrm{~h}$ in $1 \mathrm{~mL}$ of acetate buffer $(0.3 \mathrm{M}$ aqueous acetic acid and $0.2 \mathrm{M}$ aqueous sodium acetate), followed by filtration through a $0.45 \mu \mathrm{m}$ PES membrane. The samples were injected $(100 \mu \mathrm{L})$ into the GPC at a flow rate of $1 \mathrm{~mL} / \mathrm{min}$ at $30^{\circ} \mathrm{C}$. Runtime was $40 \mathrm{~min}$. Pullulan P20 (180-1,220,000 Da) was used as a reference and stability control. Data were analyzed on Astra software. When necessary, data fitting was performed using exponential degree 2 and forward extrapolation.

\subsection{Synthesis of Polymers}

Preparation of dCS: Commercial CS (200 mg) was suspended in a microwave vial containing $20 \mathrm{~mL}$ of $1 \mathrm{M} \mathrm{HCl}$ aqueous solution, resulting in a CS solution at $1 \% w / v$. The vial was placed in the microwave reactor and the depolymerization program was started under a constant stirring at $300 \mathrm{rpm}$. Video monitoring of the solution showed that the sample was entirely solubilized after $1 \mathrm{~min}\left(\mathrm{~T}^{\circ} \mathrm{C}\right.$ reaching $\left.60-70^{\circ} \mathrm{C}\right)$. The depolymerization program was composed of the following steps: heat as fast as possible to $100{ }^{\circ} \mathrm{C}$, hold at $100{ }^{\circ} \mathrm{C}$ for $19 \mathrm{~min}$, cool down to $35^{\circ} \mathrm{C}$ as fast as possible. Once the $\mathrm{dCS}$ solution reached $30^{\circ} \mathrm{C}$, the solution was neutralized in two steps: first a $10 \mathrm{M} \mathrm{NaOH}$ aqueous solution was added dropwise until the solution started to become blurry and reached $\mathrm{pH} 6.7$ (pH-meter monitoring). The suspension was left to equilibrate at $\mathrm{rt}$ for $15 \mathrm{~min}$ before being centrifuged (4700 rpm, $20^{\circ} \mathrm{C}, 10 \mathrm{~min}$ ). Only the liquid fraction was recovered. Its $\mathrm{pH}$ was then further increased to 7.0 with dropwise addition of a $0.05 \mathrm{M} \mathrm{NaOH}$ aqueous solution. The white suspension was centrifuged a second time under the same conditions to remove the second 
precipitate, if any. The resulting liquid part was transferred to a dialysis membrane (MWCO $3.5 \mathrm{kDa}$ ) and dialyzed against water for 3 days. After freeze drying, a white aerated solid was obtained $(25 \mathrm{mg}, \mathrm{DD}=79 \%, \mathrm{Mw}=8.3 \mathrm{kDa}) .{ }^{1} \mathrm{H} \mathrm{NMR}\left(400 \mathrm{MHz}, \mathrm{D}_{2} \mathrm{O} / \mathrm{CD}_{3} \mathrm{COOD}\right.$ 1/1): $\delta 4.94(\mathrm{~d}, \mathrm{~J}=8.6 \mathrm{~Hz}, 0.79 \mathrm{H},-\mathrm{OCH}-\mathrm{O}-), 4.63$ (br, 0.21H, -OCH-O-), 4.10-3.48 (m, 5H), $3.25\left(\mathrm{t}, \mathrm{J}=9.0 \mathrm{~Hz}, 1 \mathrm{H},-\mathrm{CHNH}_{2}\right) .{ }^{1} \mathrm{H}$ NMR $\left(400 \mathrm{MHz}, \mathrm{D}_{2} \mathrm{O}\right): \delta 4.59$ (br, $\left.1 \mathrm{H},-\mathrm{OCH}-\mathrm{O}-\right)$, 4.08-3.42 (m, 5H), 2.85 (br, 1H, -CHNH-), 2.07 (s, 3H, -NHCOCH $)_{3}$. IR ( $\left.\mathrm{cm}^{-1}\right)$ : 3292, 2876, 1644, 1376, 1320, 1151, 1062, 1030, 896, 666.

Synthesis of dCS-Suc: dCS (DD $=79 \%, 1.00 \mathrm{~g}, 4.72 \mathrm{mmol}$ of reactive glucosamine units, 1.00 equiv.) was dissolved in water $(100 \mathrm{~mL})$ at $\mathrm{rt}$ and further acidified with $\mathrm{HCl}$ $37 \%$ aqueous solution $(0.300 \mathrm{~mL}$ added dropwise to reach complete dissolution). To this solution were slowly added pyridine $(5.70 \mathrm{~mL}, 70.8 \mathrm{mmol}$, and 15.0 equiv.) and succinic anhydride (477 mg, $4.77 \mathrm{mmol}$, and 1.01 equiv.). After $20 \mathrm{~min}$, dissolution was complete and $\mathrm{pH}$ of the solution was controlled at 7 . After $1 \mathrm{~h}$ of additional stirring at $\mathrm{rt}$, the mixture was transferred to a dialysis tube (MWCO $3.5 \mathrm{kDa}$ ) and dialyzed against water for 3 days. After centrifugation $\left(4700 \mathrm{rpm}, 19^{\circ} \mathrm{C}\right.$, and $\left.10 \mathrm{~min}\right)$, the supernatant was recovered and lyophilized. dCS-Suc was obtained as a white aerated solid (913 $\mathrm{mg}, \mathrm{GD}_{\mathrm{Suc}}=63 \%$ ). ${ }^{1} \mathrm{H}$ NMR (600 MHz, D $\left.2 \mathrm{O} / \mathrm{CD}_{3} \mathrm{COOD} 1 / 1\right): \delta 5.20$ (br, 0.05H, -OCH-O-), 4.94 (br, 0.16H, -OCH-O-), 4.59 (br, 0.79H, -OCH-O-), 4.04-3.47 (m, 5H), 3.21 (br, 1H, -CHNH-), 2.66 (br, $\left.4 \mathrm{H},-\mathrm{CH}_{2} \mathrm{CH}_{2} \mathrm{CO}\right) .{ }^{1} \mathrm{H}$ NMR $\left(400 \mathrm{MHz}, \mathrm{D}_{2} \mathrm{O}\right): \delta 5.19$ (br, $\left.0.05 \mathrm{H},-\mathrm{OCH}-\mathrm{O}-\right), 4.88$ (br, $0.16 \mathrm{H}$, -OCH-O-), 4.58 (br, 0.79H, -OCH-O), 3.98-3.45 (m, 5H), 3.16 (br, 1H, -CHNH-), 2.58 (br, 4H, $\left.-\mathrm{CH}_{2} \mathrm{CH}_{2} \mathrm{CO}\right), 2.05$ (br, 3H, $\left.-\mathrm{NHCOCH}_{3}\right)$. IR $\left(\mathrm{cm}^{-1}\right)$ : 3270, 2930, 1645, 1549, 1378, 1154, 1064, $1029,898,622$.

Synthesis of dCS-Suc-BPEI: dCS-Suc (DD = 83\%, GD Suc $=45 \%, 200 \mathrm{mg}, 1.03 \mathrm{mmol}$ of reactive units, and 1.00 equiv.) was dissolved in water $(10 \mathrm{~mL})$ for $15 \mathrm{~min}$ at rt. DMTMM (285 mg, $1.03 \mathrm{mmol}$, and 1.00 equiv.) was added to this solution, which was stirred for $10 \mathrm{~min}$ at $\mathrm{rt}$. To the clear solution was added dropwise a solution of BPEI (1.8 kDa, $2.87 \mathrm{~g}, 0.638 \mathrm{mmol}$, and 0.620 equiv.) dissolved in $10 \mathrm{~mL}$ of water. After $3 \mathrm{~h}$ of stirring, the very clear reaction mixture was transferred to a dialysis tube (MWCO $14 \mathrm{kDa}$ ) and dialyzed against water for 3 days. After centrifugation $\left(4700 \mathrm{rpm}, 18^{\circ} \mathrm{C}\right.$, and $\left.10 \mathrm{~min}\right)$, the supernatant was recovered and lyophilized. dCS-Suc-BPEI was obtained as a white aerated solid (650 mg, GD $\mathrm{BPEI}=18 \%$ ). ${ }^{1} \mathrm{H}$ NMR (400 MHz, $\left.\mathrm{D}_{2} \mathrm{O} / \mathrm{CD}_{3} \mathrm{COOD} 1: 1\right): \delta 5.25$ (br, 0.05H, -OCH-O-), 4.94 (br, 0.38H, -OCH-O-), 4.60 (br, 0.57H, -OCH-O-), 4.13-2.75 (m, 36H), 2.69 (br, $\left.4 \mathrm{H},-\mathrm{CH}_{2} \mathrm{CH}_{2} \mathrm{CO}\right) .{ }^{1} \mathrm{H}$ NMR $\left(400 \mathrm{MHz}, \mathrm{D}_{2} \mathrm{O}\right): \delta 4.58$ (br, $\left.1 \mathrm{H},-\mathrm{OCH}-\mathrm{O}-\right), 4.01-3.08(\mathrm{~m}, 6 \mathrm{H})$, 3.07-2.47 (br, 30H), 2.06 (s, 3H, $\left.\mathrm{NHCOCH}_{3}\right)$.

Synthesis of dCS-Suc-LPEI: dCS-Suc (DD = 79\%, GD Suc $_{1}=63 \%, 200 \mathrm{mg}, 0.542 \mathrm{mmol}$ of reactive units, and 1.00 equiv.) was dissolved in water (20 mL) over $15 \mathrm{~min}$ from rt to $50{ }^{\circ} \mathrm{C}$. DMTMM (150 mg, $0.542 \mathrm{mmol}$, and 1.00 equiv.) was added in one portion, followed by heating of the reaction mixture at $60{ }^{\circ} \mathrm{C}$ for $10 \mathrm{~min}$ (clear solution). LPEI (677.5 $\mathrm{mg}, 0.271 \mathrm{mmol}$, and 0.50 equiv.) was added in 4 equal portions and under vigorous stirring (>500 rpm). $\mathrm{pH}$ was controlled at 10 . After $3 \mathrm{~h}$ of heating at $60^{\circ} \mathrm{C}$ under vigorous stirring, the mixture was cooled down and split into 6 dialysis tubes (MWCO $7 \mathrm{kDa}$ ). They were filled with additional water $(30 \mathrm{~mL})$ and dialyzed against water for 3 days. After centrifugation $\left(4700 \mathrm{rpm}, 18^{\circ} \mathrm{C}\right.$, and $\left.10 \mathrm{~min}\right)$, the supernatant was recovered and lyophilized. dCS-Suc-LPEI was obtained as of a white aerated solid (135 mg, GD $\left.\mathrm{LPEI}_{\mathrm{m}}=14 \%\right)$. ${ }^{1} \mathrm{H}$ NMR (600 MHz, D $\left.2 \mathrm{O} / \mathrm{CD}_{3} \mathrm{COOD} 1 / 1\right)$ : $\delta 4.93$ (br, 0.16H, -OCH-O-), 4.60 (br, 0.84H, -OCH-O-), 4.14-2.96 (m, 39H), 2.66 (br, 4H, $\left.-\mathrm{CH}_{2} \mathrm{CH}_{2} \mathrm{CO}\right) .{ }^{1} \mathrm{H}$ NMR $\left(400 \mathrm{MHz}, \mathrm{D}_{2} \mathrm{O}\right): \delta$ 4.59 (br, 0.84H, -OCH-O-), 4.48 (br, 0.16H, -OCH-O-), 4.12-2.63 (m, 39H), 2.62-2.44 (br, 4H, $\left.-\mathrm{CH}_{2} \mathrm{CH}_{2} \mathrm{CO}\right), 2.06$ (s, 3H, NHCOCH 3$)$. IR ( $\left.\mathrm{cm}^{-1}\right)$ : 3272, 2917, 2847, 1651, 1555, 1464, 1408, 1372, 1303, 1109, 1063, 1030, 899, 812, 646.

Synthesis of dCS-NSucBPEI-OPEG-SH: dCS-Suc-BPEI (DD $=80 \%, \mathrm{GD}_{\mathrm{Suc}}=47 \%$, $\mathrm{GD}_{\mathrm{BPEI}}=11 \%, 30.0 \mathrm{mg}, 0.0724 \mathrm{mmol}$, and 1.00 equiv. $)$ was dissolved in dry DMSO (2.5 $\mathrm{mL}$ ) over $15 \mathrm{~min}$ at rt. After addition of CDI (12.0 mg, $0.0724 \mathrm{mmol}$, and 1.00 equiv.), the white solution was stirred at rt for $30 \mathrm{~min}$. A solution of PEG (2 kDa, $29 \mathrm{mg}, 0.0145 \mathrm{mmol}$, and 0.200 equiv.) in $0.5 \mathrm{~mL}$ of DMSO was then added dropwise. The reaction mixture 
was stirred at $\mathrm{rt}$ for $19 \mathrm{~h}$, before being dialyzed against water for 3 days (MWCO $14 \mathrm{kDa}$ ). The solution remained homogeneous over time. It was then centrifuged $\left(4700 \mathrm{rpm}, 18^{\circ} \mathrm{C}\right.$, and $10 \mathrm{~min}$ ) and the supernatant was recovered. dCS-NSucBPEI-OPEG-SH was obtained after freeze drying as a white aerated solid $\left(37.3 \mathrm{mg}, \mathrm{GD}_{\mathrm{PEG}}=26 \%\right) .{ }^{1} \mathrm{H} \mathrm{NMR}(600 \mathrm{MHz}$, $\mathrm{D}_{2} \mathrm{O} / \mathrm{CD}_{3} \mathrm{COOD} 1: 1$ ): $\delta 4.94$ (br, 0.33H, -OCH-O-), 4.60 (br, 0.67H, -OCH-O-), 4.02-2.74 (m, $70 \mathrm{H}), 2.66$ (br, 4H, - $\left.\mathrm{CH}_{2} \mathrm{CH}_{2} \mathrm{CO}\right) .{ }^{1} \mathrm{H} \mathrm{NMR}\left(400 \mathrm{MHz}, \mathrm{D}_{2} \mathrm{O}\right): \delta 4.65-4.43$ (br, $\left.1 \mathrm{H},-\mathrm{OCH}-\mathrm{O}-\right)$, 4.00-2.41 (m, 66H), $2.06\left(\mathrm{~s}, 3 \mathrm{H}, \mathrm{NHCOCH}_{3}\right)$.

Synthesis of dCS-NSuc-OPEG-SH: To a solution of dCS-Suc (DD $=85 \%, \mathrm{GD}_{\mathrm{Suc}}=44 \%$, $100 \mathrm{mg}, 0.473 \mathrm{mmol}$ of reactive units, and 1.00 equiv.) in $6 \mathrm{~mL}$ of dry DMSO, was added at rt and in one portion CDI (77 mg, $0.473 \mathrm{mmol}$, and 1.00 equiv.). The white homogenous mixture was stirred at $\mathrm{rt}$ for $30 \mathrm{~min}$. DIPEA (41 $\mu \mathrm{L}, 0.236 \mathrm{mmol}$, and 0.500 equiv.) was then added to the reaction mixture, followed by a dropwise addition of a solution of PEG (2 kDa, $194 \mathrm{mg}, 0.0946 \mathrm{mmol}$, and 0.200 equiv.) in DMSO (4 mL). After $17 \mathrm{~h}$ of stirring at rt, the white mixture was transferred to a dialysis tube (MWCO $7 \mathrm{kDa})$ and dialyzed against water for 3 days. The solution was centrifuged $\left(4700 \mathrm{rpm}, 21^{\circ} \mathrm{C}\right.$, and $10 \mathrm{~min}$ ) and the supernatant was lyophilized. dCS-NSuc-OPEG-SH was obtained as a white and aerated solid (200 mg, GD PEG = 14\%). ${ }^{1} \mathrm{H} \mathrm{NMR}\left(400 \mathrm{MHz}, \mathrm{D}_{2} \mathrm{O} / \mathrm{CD}_{3} \mathrm{COOD} 1: 1\right): \delta 4.93(\mathrm{br}, 0.41 \mathrm{H}$, $\mathrm{OCH}-\mathrm{O}-), 4.60$ (br, 0.59H, OCH-O-), 4.18-3.03 (m, 30H), 2.94 (t, 2H, $\left.-\mathrm{CH}_{2} \mathrm{CH}_{2} \mathrm{SH}\right), 2.66$ (br, $\left.4 \mathrm{H},-\mathrm{CH}_{2} \mathrm{CH}_{2} \mathrm{CO}\right)$.

Synthesis of dCS-NSucLPEI-OPEG-SH: To a clear solution of dCS-NSuc-OPEG-SH $\left(\mathrm{DD}=85 \%, \mathrm{GD}_{\mathrm{Suc}}=44 \%, \mathrm{GD}_{\mathrm{PEG}}=14 \%, 50.0 \mathrm{mg}, 0.100 \mathrm{mmol}\right.$, and 1.00 equiv. $) 8 \mathrm{~mL}$ of water was added at rt and in one portion DMTMM (13.9 mg, $0.050 \mathrm{mmol}$, and 0.500 equiv.). After $15 \mathrm{~min}$ of stirring from rt to $60{ }^{\circ} \mathrm{C}$, LPEI $(2.5 \mathrm{kDa}, 125 \mathrm{mg}, 0.050 \mathrm{mmol}$, and 0.500 equiv.) was added to the reaction mixture in 4 portions. Finally, DIPEA $(3.5 \mu \mathrm{L}, 0.020 \mathrm{mmol}$, 0.200 equiv.) was added and the reaction mixture was stirred at $60{ }^{\circ} \mathrm{C}$ for $3 \mathrm{~h}$. After cooling down, the homogenous mixture was split into two dialysis tubes (MWCO $7 \mathrm{kDa}$ ) and dialyzed against water. The solution was centrifuged $\left(4700 \mathrm{rpm}, 20^{\circ} \mathrm{C}\right.$, and $\left.10 \mathrm{~min}\right)$, and the supernatant was freeze dried to yield dCS-NSucLPEI-OPEG-SH as a white aerated solid (37.0 mg, GD $\mathrm{LPEI}=22 \%) .{ }^{1} \mathrm{H}$ NMR (600 MHz, $\left.\mathrm{D}_{2} \mathrm{O} / \mathrm{CD}_{3} \mathrm{COOD} 1: 1\right): \delta 4.95$ (br, 0.41H, OCH-O-), 4.61 (br, 0.59H, OCH-O-), 4.12-3.20 (m, 86H), 2.67 (br, $4 \mathrm{H},-\mathrm{CH}_{2} \mathrm{CH}_{2} \mathrm{CO}$ ).

\subsection{Polymer Complexation with DNA}

The dCS-Suc-PEI copolymers were reconstituted in purified water and supported with $\mathrm{HCl}$, when required, to a minimum $\mathrm{pH}$ of four. For used concentration refer to Table 2 . The polymer was diluted in glucose solution and added to the DNA, vortexed, resulting in a final $5 \%(w / v)$ glucose solution, before incubating for $15 \mathrm{~min}$ at room temperature. The ability of polymers to condensate DNA was confirmed by agarose gel electrophoresis. To $20 \mu \mathrm{L}$ polyplexes at various $\mathrm{c} / \mathrm{p}$ ratios with a final concentration of $15 \mu \mathrm{g}$ DNA/mL, $4 \mu \mathrm{L}$ DNA sample-buffer was added (15\% Ficoll400 and $0.1 \%$ Bromophenol blue) and administered to electrophoresis on a $0.7 \%$ agarose gel (including $1 \mu \mathrm{g} / \mathrm{mL}$ ethidium bromide) during $90 \mathrm{~min}$ at an electric potential of $90 \mathrm{~V}$ in tris-borate-EDTA buffer (TBE). A molecular-weight size marker (Precision Plus Protein Dual Color Standards, Bio-Rad, Hércules, CA, USA) was included as reference. DNA bands were imaged with the ChemiDoc MP Imaging system using Image lab V6.1 software (Bio-Rad).

To evaluate the accessibility of complexed DNA, polyplex solutions at various $\mathrm{c} / \mathrm{p}$ ratios were added to $20 \mu \mathrm{g}$ DNA/mL and RedSafe nucleic acid staining solution (1:66,666, iNtRON Biotechnology, Sagimakgol-ro, Korea). Fluorescence emission was measured using an UV/VIS microplate reader (Ex: 309 nm, Em: 537 nm). Results were normalized to free DNA.

\subsection{Colloidal Stability}

Hydrodynamic diameter D and polydispersity index (PDI) were determined by dynamic light scattering (DLS) and $\zeta$-potential was determined by electrophoretic light scattering using Zetasizer Nano-ZS Zen3600 and Zetasizer Ultra with the Zetasizer DTS 
and ZS explorer software, respectively (Malvern Panalytical, Worcestershire, UK). For $\zeta$-potential measurements, polyplexes were diluted in a $5 \%$ glucose solution.

\subsection{Transfection}

Transfection experiments were assessed in 24-multiwell plates with $2 \times 10^{4} \mathrm{HuH}-7$ cells/well. Subsequently, $100 \mu \mathrm{L}$ polymer solution was added per well at a final concentration of $10 \mu \mathrm{g}$ DNA/mL.

Luciferin assay was conducted to determine transgene expression. Forty-eight hours after addition of polyplex solution encoding firefly luciferase, cells were washed with phosphate-buffered saline (PBS) and lysed with $60 \mu \mathrm{L}$ luciferase cell culture lysis reagent (25 mM Tris-phosphate pH 7.8, 2 mM DTT, 2 mM DCTA, 50\% glycerol, 5\% Triton X-100) on ice for $15 \mathrm{~min}$. Cell lysate was centrifuged $(21,000 \times g, 3 \mathrm{~min})$ and $20 \mu \mathrm{L}$ supernatant was measured using a bioluminescence microplate reader after addition of $100 \mu \mathrm{L}$ D-luciferin solution $(570 \mu \mathrm{M})$. Transfection experiments were normalized to protein concentration of cell lysate supernatants. Protein concentration was quantified by UV-absorption at $280 \mathrm{~nm}$.

Quantification of delivered DNA was conducted by quantitative polymerase-chain reaction (qPCR). Twenty-four hours after addition of polyplex solution with nanovectorDNA encoding firefly luciferase, transfected DNA was extracted using QIAprep Spin Miniprep Kit (Quiagen, Venlo, The Netherlands) according to the manufacturer's protocol. Subsequently, qPCR was performed using KAPA SYBR Fast qPCR Master Mix (KAPA Biosystems, Wilmington, MA, USA), equal voluminal of isolated DNA, and the following primers: Luciferase forward 5'-AACAGGTTGAACTGCTGATCC-3' and Luciferase reverse $5^{\prime}$-ACAAGATGTGCGAACTCGATATT-3' . qPCR reactions were performed applying 40 cycles of $95^{\circ} \mathrm{C}$ for $15 \mathrm{~s}$ and $60{ }^{\circ} \mathrm{C}$ for $1 \mathrm{~min}$, using a Rotor-Gene Cycler (Corbett research, Sydney, New South Wales, Australia). Readout data were normalized to the DNA calibration curve.

The number of transfected cells was quantified using flow cytometry. Forty-eight hours after addition of the polyplex solution encoding eGFP, cells were trypsinized and resuspended in FACS-Buffer (1\% FCS, $2.5 \mathrm{mM}$ EDTA, 0.05\% $\mathrm{NaN}_{3}$ in PBS) containing 7 aminoactinomycin D (7-AAD, $2 \mu \mathrm{g} / \mathrm{mL})$ and annexin $\mathrm{V}(1 \mu \mathrm{g} / \mathrm{mL})$. For the flow cytometry, singlets, $7 \mathrm{AAD}$, and Annexin $\mathrm{V}$ negative cells were gated and analyzed for eGFP expression. A total of 10,000 cells per sample was analyzed using FACS Canto II (BD Bioscience, San Jose, CA, USA) and data was subsequently processed using FlowJo software (TreeStar, Ashland, OR, USA).

\subsection{Confocal Microscopy}

HuH-7 cells were cultured in Ibidi $\mu$-Slide (Ibidi, Martinsried, Germany). Forty-eight hours after addition of polyplex solution encoding eGFP by nanovector-DNAs, cell nuclei were stained using Hoechst-33342 $(2 \mu \mathrm{g} / \mathrm{mL})$ in D-PBS for $10 \mathrm{~min}$ at $37^{\circ} \mathrm{C}$ and thereafter incubated in fresh media. Samples were analyzed on an Olympus FluoView3000 inverted confocal microscope (Olympus, Tokyo, Japan) with an UPLSAPO $30 \times$ silicon oil-immersion objective (NA 1.05). Images were further processed using Olympus FV31S-SW (Olympus) and Omero version 5.4.10 software [72].

\subsection{Cytotoxicity}

Cytotoxicity of polyplexes was assessed by a cell viability assay. On a 96-multiwell plate $1.5 \times 103 \mathrm{HuH}-7$ cells/well were seeded and polyplexes of $10 \mu \mathrm{g}$ DNA/mL with various $c / p$ ratios were added to fresh media. Terfenadine $(1-10 \mathrm{nM})$ was administered as a negative control. Following $48 \mathrm{~h}$ incubation, $20 \mu \mathrm{L}$ of MTS reagent was added to each well and incubated for $2 \mathrm{~h}$ at $37^{\circ} \mathrm{C}$. Conversion of MTS by living cells to a metabolite was monitored by a colorimetric reaction at $490 \mathrm{~nm}$ using an UV/VIS microplate reader. 


\subsection{Retrograde Intrabiliary Infusion in Mice}

Animal experiments conducted under license ZH082/19 (31232), were approved by the State Veterinary Office of Zürich (approved on 29 August 2019) and carried out according to the guidelines of the Swiss Law of Animal Protection, the Swiss Federal Act on Animal Protection (1978), and the Swiss Animal Protection Ordinance (1981). Wildtype C57BL/6JRccHsd male mice aged 6-8 weeks (20-24 g) were obtained from Envigo, Horst, Netherlands. Mice were maintained under a 12-h dark-light cycle at a standardized environment with controlled humidity and temperature. They had ad libitum access to standard chow and water. For pain relief, mice received a combination of $0.1 \mathrm{mg} / \mathrm{kg}$ buprenorphine (Temgesic, Indivior Schweiz AG, Baar, Switzerland) and $5 \mathrm{mg} / \mathrm{kg}$ carprofen (Rimadyl, Pfizer, New York, NY, USA) subcutaneously $30 \mathrm{~min}$ before and after surgery. For anesthesia, a nose mask was fixed with continued treatment of $2-3 \%$ isoflurane. The surgical intervention was adapted from Berntsen et al. [73]. Following a midline laparotomy, polyethylene tubing (Smiths Medical, Adliswil, Switzerland) was carefully inserted into the gallbladder and placed just proximal to the junction of the cystic duct. A silk tie was used to secure the infusion tubing. The common bile duct was obstructed by a micro vessel clamp (60 g; Fine Science Tools, Heidelberg, Germany) to ensure fluid-injection directly into the liver and at the same time to prevent fluid from entering the pancreas and duodenum. A total volume of $400 \mu \mathrm{L}$ containing either in vivo-jetPEI at c/p 1.1 (Polyplus, Illkirch, France) or dCS-Suc-LPEI-14 at c/p 2 (batch \#LN276), each encapsulating $1 \mu \mathrm{g}$ of nanovector-DNA n.P3Luc1 in 5\% glucose solution, was administered. Duration of infusion was $10 \mathrm{~min}$ using an infusion pump (Harvard Apparatus, Holliston, MA, USA) and a normo-dynamic infusion rate of $0.04 \mathrm{~mL} / \mathrm{min}$. After infusion, the micro vessel clamp was removed from the common bile duct. The infusion tubing was withdrawn from the gallbladder, the cystic duct was ligated, and a cholecystectomy was performed. To suppress the inflammatory response, a single dose of dexamethasone (10 mg/kg) (Mephameson, Mepha Pharma AG, Basel, Switzerland) was infused i.p. $15 \mathrm{~h}$ prior to surgical intervention as indicated.

\subsection{In Vivo Imaging of Gene Expression and Assessment of Liver Specific Toxicity}

Mice were i.p. injected with $150 \mathrm{mg} / \mathrm{kg}$ D-luciferin potassium salt (Gold Biotechnology, St. Louis, MO, USA). After D-luciferin injection, bioluminescence was monitored using a bioimaging system (IVIS 200, Perkin Elmer, Santa Clara, CA, USA). Signals were quantified using Living Image 3.2 software (Perkin Elmer). After termination of the experiment on day 3 , blood samples were collected from the vena cava. Alanine aminotransferase (ALT), alkaline phosphatase (ALP), and direct/total bilirubin levels in serum samples were analyzed as indicated by the manufacturer (Abbott Alinity C System, Abbot Laboratories, Chicago, IL, USA).

\section{Conclusions}

In the present work, small molecular weight depolymerized CS was used as a platform for sequential and selective conjugation of both amino and hydroxyl functionalities with PEI and PEG derivatives. These cationic copolymers were assessed for their DNA condensation ability and the resulting polyplexes were evaluated with respect to key parameters such as colloidal stability, in vitro and in vivo transfection efficiency and cytotoxicity. We conclude that intrabiliary administration of a non-integrating DNA vector under the control of a liver-specific promoter allows for an efficient transfection of the liver. We propose that the transfection efficiency can be further optimized by functionalization of the polymer conjugates. This could include the conjugation of tissue-specific targeting moieties and cellpenetrating peptides at the surface of the polyplexes-although challenging, this solution would allow systemic administration. Alternatively, intrabiliary injection is a minimal invasive endoscopic procedure, comparable to endoscopic stenting of the bile duct. Upon chemical modification of polyplexes to reduce and minimize toxicity, this route offers interesting options with respect to a future clinical evaluation of the presented non-viral gene therapy approach. 
Supplementary Materials: The following are available online at https://www.mdpi.com/article/10 .3390 /ijms22083828/s1, Table S1: Screening of coupling agents and reaction conditions for the conjugation of dCS to BPEI, Scheme S1: Synthetic strategies for the preparation of dCS-BPEI conjugates, Figure S1: Detailed representation of PEI conjugation sites to dCS-Suc, Scheme S2: Strategies for the dual functionalization of dCS with PEI and PEG polymers, Table S2: Selection of the optimal synthetic sequence for the functionalization of amino and hydroxyl groups of dCS, NMR analyses and calculations for dCS and derivatives, Table S3: DNA exclusion assay to evaluate accessibility of DNA complexed with polymeric conjugates, Table S4: Scale up and reproducibility of dCS-SucLPEI synthesis, Figure S2: Quantitative analysis of in vitro GFP expression of the lead candidate dCS-Suc-LPEI-14.

Author Contributions: Conceptualization, methodology, investigation, L.N., J.C., M.W., C.M.A.J., P.D., T.E., and H.M.G.-C.; validation, all authors; investigation, L.N., J.C., M.W., C.M.A.J., P.D., and H.M.G.-C.; data curation, all authors; writing-original draft preparation, L.N., J.C., M.W., C.M.A.J., P.D., H.M.G.-C.; writing - review and editing, all authors; supervision, project administration and funding acquisition, B.T., S.G.-L., and J.H. All authors have read and agreed to the published version of the manuscript.

Funding: This research was funded by the Swiss National Science Foundation (Sinergia Grant CRSII5_180257). The APC was funded by the Swiss National Science Foundation.

Institutional Review Board Statement: Animal experiments conducted under license ZH082/19 were approved by the State Veterinary Office of Zürich and carried out according to the guidelines of the Swiss Law of Animal Protection, the Swiss Federal Act on Animal Protection (1978), and the Swiss Animal Protection Ordinance (1981).

Informed Consent Statement: Not applicable.

Data Availability Statement: Raw data will be accessible from zenodo (https://zenodo.org/).

Acknowledgments: The authors acknowledge the scientific and technical assistance of Aurélien Bornet (ISIC NMR Platform, EPFL), and Adrian S. Gheata for his preliminary synthetic developments.

Conflicts of Interest: The authors declare no conflict of interest. The funders had no role in the design of the study; in the collection, analyses, or interpretation of data; in the writing of the manuscript, or in the decision to publish the results.

$\begin{array}{ll}\text { Abbreviations } \\ \text { 7-AAD } & \text { 7-Aminoactinomycin D } \\ \text { ALP } & \text { Alkaline phosphatase } \\ \text { ALT } & \text { Alkaline transaminase } \\ \text { BPEI } & \text { Branched polyethylenimine } \\ \text { CDI } & \text { 1,1'-carbonyldiimidazole } \\ \text { c/p } & \text { weight ratio of polymer [c] to nucleic acid [p] } \\ \text { CS } & \text { Chitosan } \\ \text { dCS } & \text { Depolymerized chitosan } \\ \text { DD } & \text { Deacetylation degree } \\ \text { DIPEA } & \text { N,N-diisopropylethylamine } \\ \text { DLS } & \text { Dynamic light scattering } \\ \text { DMSO } & \text { Dimethyl sulfoxide } \\ \text { DMTMM } & \text { 4-(4,6-dimethoxy-1,3,5-triazin-2-yl)-4-methyl-morpholinium chloride } \\ \text { DNA } & \text { Deoxyribonucleic acid } \\ \text { DOSY } & \text { Diffusion order spectroscopy } \\ \text { DSC } & \text { N-N' disuccinimidyl carbonate } \\ \text { EDC } & \text { 1-ethyl-3-(3-dimethylaminopropyl)carbodiimide } \\ \text { ELS } & \text { Electrophoretic light scattering } \\ \text { FACS } & \text { Fluorescence-activated cell sorting } \\ \text { FTIR } & \text { Fourier-transform infrared spectroscopy } \\ \end{array}$




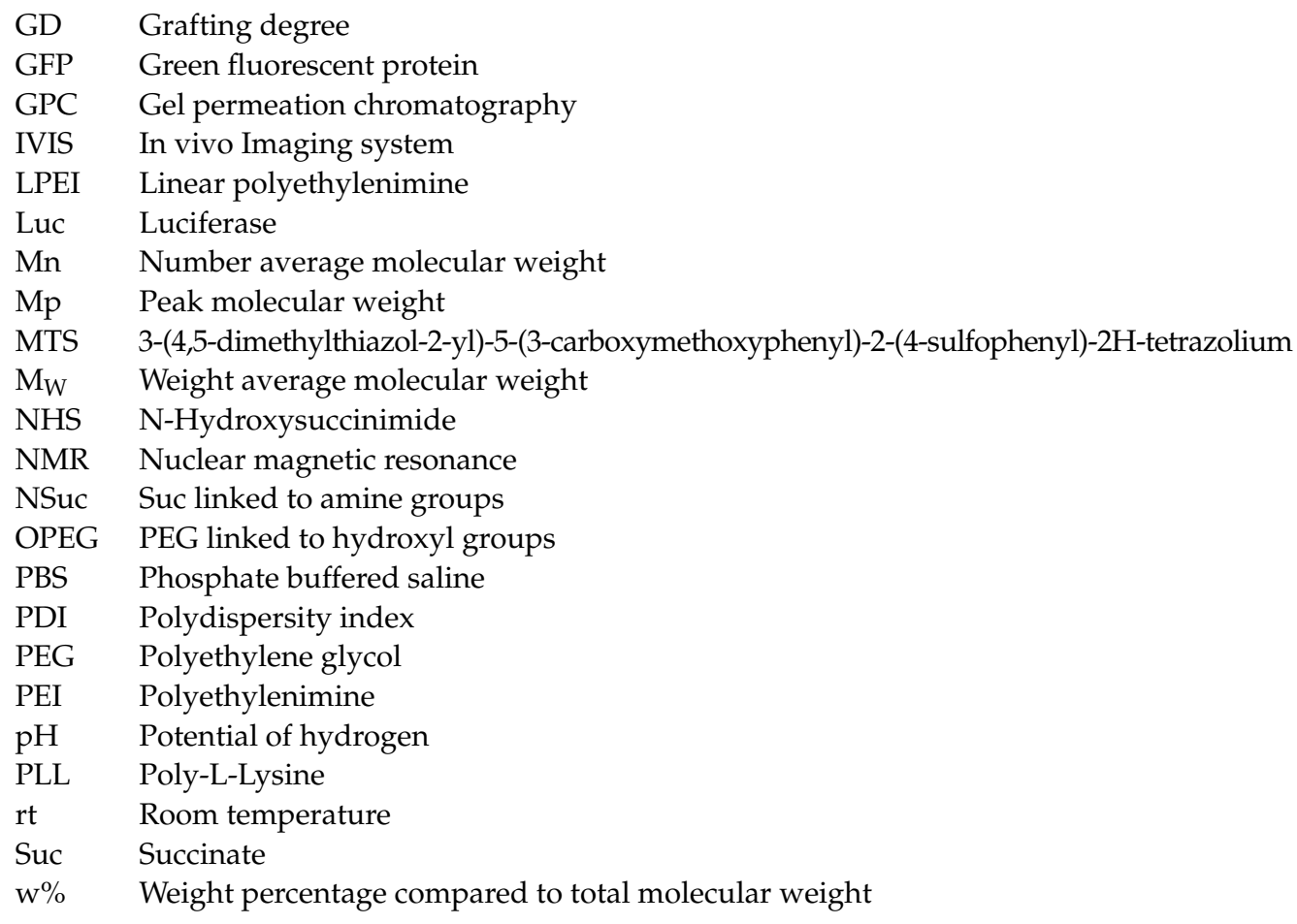

\section{References}

1. Mendell, J.R.; Al-Zaidy, S.A.; Rodino-Klapac, L.R.; Goodspeed, K.; Gray, S.J.; Kay, C.N.; Boye, S.L.; Boye, S.E.; George, L.A.; Salabarria, S.; et al. Current clinical applications of in vivo gene therapy with AAVs. Mol. Ther. 2021, 29, 464-488. [CrossRef]

2. Dunbar, C.E.; High, K.A.; Joung, J.K.; Kohn, D.B.; Ozawa, K.; Sadelain, M. Gene therapy comes of age. Science 2018, 359, eaan4672. [CrossRef]

3. Anzalone, A.V.; Koblan, L.W.; Liu, D.R. Genome Editing with CRISPR-Cas Nucleases, Base Editors, Transposases and prime editors. Nat. Biotech. 2020, 38, 824-844. [CrossRef]

4. Santos-Carballal, B.; Fernández Fernández, E.; Goycoolea, F. Chitosan in Non-Viral Gene Delivery: Role of structure, characterization methods, and insights in cancer and rare diseases therapies. Polymers 2018, 10, 444. [CrossRef]

5. Hardee, C.L.; Arévalo-Soliz, L.M.; Hornstein, B.D.; Zechiedrich, L. Advances in non-viral DNA vectors for gene therapy. Genes 2017, 8, 65. [CrossRef]

6. Aravalli, R.N.; Belcher, J.D.; Steer, C.J. Liver-Targeted Gene therapy: Approaches and challenges. Liver Transplant. 2015, 21, 718-737. [CrossRef] [PubMed]

7. Ibraheem, D.; Elaissari, A.; Fessi, H. Gene therapy and DNA delivery systems. Int. J. Pharm. 2014, 459, 70-83. [CrossRef] [PubMed]

8. Jin, L.; Zeng, X.; Liu, M.; Deng, Y.; He, N. Current Progress in Gene Delivery Technology based on chemical methods and nano-carriers. Theranostics 2014, 4, 240-255. [CrossRef] [PubMed]

9. Zhang, S.; Xu, Y.; Wang, B.; Qiao, W.; Liu, D.; Li, Z. Cationic Compounds Used in lipoplexes and polyplexes for gene delivery. J. Control. Release 2004, 100, 165-180. [CrossRef] [PubMed]

10. Kircheis, R.; Wightman, L.; Wagner, E. Design and Gene Delivery Activity of modified polyethylenimines. Adv. Drug Deliv. Rev. 2001, 53, 341-358. [CrossRef]

11. Lungu, C.; Diudea, M.; Putz, M.; Grudziński, I. Linear and branched PEIs (Polyethylenimines) and their property space. Int. J. Mol. Sci. 2016, 17, 555. [CrossRef]

12. Virgen-Ortíz, J.J.; Dos Santos, J.C.S.; Berenguer-Murcia, Á.; Barbosa, O.; Rodrigues, R.C.; Fernandez-Lafuente, R. Polyethylenimine: A very useful ionic polymer in the design of immobilized enzyme biocatalysts. J. Mater. Chem. B. 2017, 5, 7461-7490. [CrossRef] [PubMed]

13. Hall, A.; Lächelt, U.; Bartek, J.; Wagner, E.; Moghimi, S.M. Polyplex Evolution: Understanding biology, optimizing performance. Mol Ther. 2017, 25, 1476-1490. [CrossRef]

14. Boussif, O.; Lezoualc'ht, F.; Zanta, M.A.; Mergnyt, D.; Schermant, D.; Demeneixt, B.; Behr, J.-P. A versatile vector for gene and oligonucleotide transfer into cells in culture and in vivo: Polyethylenimine. Proc. Natl. Acad. Sci. USA 1995, 92, 7297-7301. [CrossRef]

15. Hu, Y.; He, Z.; Hao, Y.; Gong, L.; Pang, M.; Howard, G.P.; Ahn, H.H.; Brummet, M.; Chen, K.; Liu, H.W.; et al. Kinetic control in assembly of plasmid DNA/polycation complex nanoparticles. ACS Nano. 2019, 13, 10161-10178. [CrossRef]

16. Yen, J.; Ying, H.; Wang, H.; Yin, L.; Uckun, F.; Cheng, J. CD44 Mediated nonviral gene delivery into human embryonic stem cells via hyaluronic-acid-coated nanoparticles. ACS Biomater. Sci. Eng. 2016, 2, 326-335. [CrossRef] [PubMed] 
17. Jiang, Z.; Cui, W.; Prasad, P.; Touve, M.A.; Gianneschi, N.C.; Mager, J.; Thayumanavan, S. Bait-and-switch supramolecular strategy to generate noncationic RNA-polymer complexes for RNA delivery. Biomacromolecules 2019, 20, 435-442. [CrossRef]

18. Singh, B.; Maharjan, S.; Park, T.E.; Jiang, T.; Kang, S.K.; Choi, Y.J.; Cho, C.S. Tuning the buffering capacity of polyethylenimine with glycerol molecules for efficient gene delivery: Staying in or out of the endosomes. Macromol. Biosci. 2015, 15, 622-635. [CrossRef]

19. Smith, S.A.; Selby, L.I.; Johnston, A.P.R.; Such, G.K. The Endosomal Escape of Nanoparticles: Toward more efficient cellular delivery. Bioconjug. Chem. 2019, 30, 263-272. [CrossRef] [PubMed]

20. Pei, D.; Buyanova, M. Overcoming Endosomal Entrapment in Drug Delivery. Bioconjug. Chem. 2019, 30, 273-283. [CrossRef] [PubMed]

21. Jeong, J.H.; Song, S.H.; Lim, D.W.; Lee, H.; Park, T.G. DNA transfection using linear poly(ethylenimine) prepared by controlled acid hydrolysis of poly(2-Ethyl-2-oxazoline). J. Control. Release 2001, 73, 391-399. [CrossRef]

22. Neu, M.; Fischer, D.; Kissel, T. Recent Advances in Rational Gene Transfer Vector Design Based on Poly(Ethylene Imine) and Its Derivatives. J. Gene Med. 2005, 7, 992-1009. [CrossRef]

23. Chen, J.; Wang, K.; Wu, J.; Tian, H.; Chen, X. Polycations for gene delivery: Dilemmas and solutions. Bioconjug. Chem. 2019, 30, 338-349. [CrossRef] [PubMed]

24. Morimoto, K.; Nishikawa, M.; Kawakami, S.; Nakano, T.; Hattori, Y.; Fumoto, S.; Yamashita, F.; Hashida, M. Molecular weightdependent gene transfection activity of unmodified and galactosylated polyethyleneimine on hepatoma cells and mouse liver. Mol. Ther. 2003, 7, 254-261. [CrossRef]

25. Wu, D.; Zhang, Y.; Xu, X.; Guo, T.; Xie, D.; Zhu, R.; Chen, S.; Ramakrishna, S.; He, L. RGD/TAT-functionalized chitosan-graftPEI-PEG gene nanovector for sustained delivery of NT-3 for potential application in neural regeneration. Acta Biomater. 2018, 72, 266-277. [CrossRef]

26. Riley, M.; Vermerris, W. Recent Advances in Nanomaterials for Gene Delivery-A Review. Nanomaterials 2017, 7, 94. [CrossRef]

27. Mastorakos, P.; Zhang, C.; Berry, S.; Oh, Y.; Lee, S.; Eberhart, C.G.; Woodworth, G.F.; Suk, J.S.; Hanes, J. Highly PEGylated DNA nanoparticles provide uniform and widespread gene transfer in the brain. Adv. Healthc. Mater. 2015, 4, 1023-1033. [CrossRef] [PubMed]

28. Kunath, K.; Von Harpe, A.; Fischer, D.; Petersen, H.; Bickel, U.; Voigt, K.; Kissel, T. Low-molecular-weight polyethylenimine as a non-viral vector for DNA delivery: Comparison of physicochemical properties, transfection efficiency and in vivo distribution with high-molecular-weight polyethylenimine. J. Control. Release 2003, 89, 113-125. [CrossRef]

29. Hill, A.B.; Chen, M.; Chen, C.K.; Pfeifer, B.A.; Jones, C.H. Overcoming gene-delivery hurdles: Physiological considerations for nonviral vectors. Trends Biotechnol. 2016, 34, 91-105. [CrossRef]

30. Shahryari, A.; Jazi, M.S.; Mohammadi, S.; Nikoo, H.R.; Nazari, Z.; Hosseini, E.S.; Burtscher, I.; Mowla, S.J.; Lickert, H. Development and clinical translation of approved gene therapy products for genetic disorders. Front. Genet. 2019, 10, 868. [CrossRef]

31. Mittal, H.; Ray, S.S.; Kaith, B.S.; Bhatia, J.K.; Sukriti; Sharma, J.; Alhassan, S.M. Recent progress in the structural modification of chitosan for applications in diversified biomedical fields. Eur. Polym. J. 2018, 109, 402-434. [CrossRef]

32. Yadav, M.; Goswami, P.; Paritosh, K.; Kumar, M.; Pareek, N.; Vivekanand, V. Seafood waste: A source for preparation of commercially employable chitin/chitosan materials. Bioresour. Bioprocess. 2019, 6. [CrossRef]

33. Radwan-Pragłowska, J.; Janus, Ł.; Piątkowski, M.; Bogdał, D.; Matysek, D. 3D Hierarchical, Nanostructured Chitosan/PLA/HA Scaffolds Doped with TiO2/Au/Pt NPs with Tunable Properties for Guided Bone Tissue Engineering. Polymers 2020, 12, 792. [CrossRef]

34. Mora-Boza, A.; López-Ruiz, E.; López-Donaire, M.L.; Jiménez, G.; Aguilar, M.R.; Marchal, J.A.; Pedraz, J.L.; Vázquez-Lasa, B.; Román, J.S.; Gálvez-Martín, P. Evaluation of glycerylphytate crosslinked semi- and interpenetrated polymer membranes of hyaluronic acid and chitosan for tissue engineering. Polymers 2020, 12, 2661. [CrossRef]

35. Yar, M.; Shahzad, S.; Shahzadi, L.; Shahzad, S.A.; Mahmood, N.; Chaudhry, A.A.; Rehman, I.U.; MacNeil, S. Heparin binding chitosan derivatives for production of pro-angiogenic hydrogels for promoting tissue healing. Mater. Sci. Eng. C 2017, 74, 347-356. [CrossRef] [PubMed]

36. Wang, Y.; Cen, C.; Chen, J.; Fu, L. MgO/carboxymethyl chitosan nanocomposite improves thermal stability, waterproof and antibacterial performance for food packaging. Carbohydr. Polym. 2020, 236, 116078. [CrossRef] [PubMed]

37. Wang, B.; Zhu, Y.; Bai, Z.; Luque, R.; Xuan, J. Functionalized chitosan biosorbents with ultra-high performance, mechanical strength and tunable selectivity for heavy metals in wastewater treatment. Chem. Eng. J. 2017, 325, 350-359. [CrossRef]

38. Yan, C.-Y.; Gu, J.-W.; Hou, D.-P.; Jing, H.-Y.; Wang, J.; Guo, Y.-Z.; Katsumi, H.; Sakane, T.; Yamamoto, A. synthesis of Tat tagged and folate modified N-succinyl-chitosan self-assembly nanoparticles as a novel gene vector. Int. J. Biol. Macromol. 2015, 72, 751-756. [CrossRef]

39. Kong, F.; Tang, C.; Yin, C. Benzylguanidine and galactose double-conjugated chitosan nanoparticles with reduction responsiveness for targeted delivery of doxorubicin to CXCR 4 positive tumors. Bioconjug. Chem. 2020, 31, 2446-2455. [CrossRef] [PubMed]

40. Kean, T.; Thanou, M. Biodegradation, biodistribution and toxicity of chitosan. Adv. Drug Deliv. Rev. 2010, 62, 3-11. [CrossRef]

41. Thomas, T.; Tajmir-Riahi, H.; Pillai, C. Biodegradable polymers for gene delivery. Molecules 2019, 24, 3744. [CrossRef] [PubMed]

42. Cao, Y.; Tan, Y.F.; Wong, Y.S.; Liew, M.W.J.; Venkatraman, S. Recent advances in chitosan-based carriers for gene delivery. Mar. Drugs 2019, 17, 381. [CrossRef] [PubMed]

43. Lavertu, M.; Méthot, S.; Tran-Khanh, N.; Buschmann, M.D. High efficiency gene transfer using chitosan/DNA nanoparticles with specific combinations of molecular weight and degree of deacetylation. Biomaterials 2006, 27, 4815-4824. [CrossRef] [PubMed] 
44. Kritchenkov, A.S.; Andranovitš, S.; Skorik, Y.A. Chitosan and its derivatives: Vectors in gene therapy. Russ. Chem. Rev. 2017, 86, 231. [CrossRef]

45. Chuan, D.; Jin, T.; Fan, R.; Zhou, L.; Guo, G. Chitosan for gene delivery: Methods for improvement and applications. Adv. Colloid Interface Sci. 2019, 268, 25-38. [CrossRef]

46. Zhang, X.; Duan, Y.; Wang, D.; Bian, F. Preparation of arginine modified PEI-conjugated chitosan copolymer for DNA delivery. Carbohydr. Polym. 2015, 122, 53-59. [CrossRef] [PubMed]

47. Hu, J.; Zhu, M.; Liu, K.; Fan, H.; Zhao, W.; Mao, Y.; Zhang, Y. A biodegradable polyethylenimine-based vector modified by trifunctional peptide R18 for enhancing gene transfection efficiency in vivo. PLoS ONE 2016, 11, e0166673. [CrossRef]

48. Journot, C.M.A.; Nicolle, L.; Lavanchy, Y.; Gerber-Lemaire, S. Selection of water-soluble chitosan by microwave-assisted degradation and $\mathrm{pH}$-controlled precipitation. Polymers 2020, 12, 1274. [CrossRef] [PubMed]

49. Gao, J.Q.; Zhao, Q.Q.; Lv, T.F.; Shuai, W.P.; Zhou, J.; Tang, G.P.; Liang, W.Q.; Tabata, Y.; Hu, Y.L. Gene-carried chitosan-linked-PEI induced high gene transfection efficiency with low toxicity and significant tumor-suppressive activity. Int. J. Pharm. 2010, 387, 286-294. [CrossRef]

50. Lu, H.; Dai, Y.; Lv, L.; Zhao, H. Chitosan-graft-polyethylenimine/DNA nanoparticles as novel non-viral gene delivery vectors targeting osteoarthritis. PLOS ONE 2014, 9, e84703. [CrossRef]

51. Aiedeh, K.; Taha, M.O. Synthesis of chitosan succinate and chitosan phthalate and their evaluation as suggested matrices in orally administered, colon-specific drug delivery systems. Arch. Pharm. 1999, 332, 103-107. [CrossRef]

52. Van Der Aa, M.A.E.M.; Huth, U.S.; Häfele, S.Y.; Schubert, R.; Oosting, R.S.; Mastrobattista, E.; Hennink, W.E.; Peschka-Süss, R.; Koning, G.A.; Crommelin, D.J.A. Cellular uptake of cationic polymer-DNA complexes via caveolae plays a pivotal role in gene transfection in COS-7 cells. Pharm. Res. 2007, 24, 1590-1598. [CrossRef]

53. Zhu, M.; Nie, G.; Meng, H.; Xia, T.; Nel, A.; Zhao, Y. Physicochemical properties determine nanomaterial cellular uptake, transport, and fate. Acc. Chem. Res. 2013, 46, 622-631. [CrossRef]

54. Hauck, T.S.; Ghazani, A.A.; Chan, W.C.W. Assessing the effect of surface chemistry on gold nanorod uptake, toxicity, and gene expression in mammalian cells. Small 2008, 4, 153-159. [CrossRef] [PubMed]

55. Danaei, M.; Dehghankhold, M.; Ataei, S.; Hasanzadeh Davarani, F.; Javanmard, R.; Dokhani, A.; Khorasani, S.; Mozafari, M.R. Impact of particle size and polydispersity index on the clinical applications of lipidic nanocarrier systems. Pharmaceutics 2018, 10, 57. [CrossRef]

56. Bonnet, M.E.; Erbacher, P.; Bolcato-Bellemin, A.L. Systemic delivery of DNA or siRNA mediated by linear polyethylenimine (L-PEI) does not induce an inflammatory response. Pharm. Res. 2008, 25, 2972-2982. [CrossRef]

57. Sadikot, R.T.; Jansen, E.D.; Blackwell, T.R.; Zoia, O.; Yull, F.; Christman, J.W.; Blackwell, T.S. High-dose dexamethasone accentuates nuclear factor-KB activation in endotoxin-treated mice. Am. J. Respir. Crit. Care Med. 2001, 164, 873-878. [CrossRef] [PubMed]

58. Lu, B.; Sun, Y.X.; Li, Y.Q.; Zhang, X.Z.; Zhuo, R.X. N-succinyl-chitosan grafted with low molecular weight polyethylenimine as a serum-resistant gene vector. Mol. Biosyst. 2009, 5, 629-637. [CrossRef] [PubMed]

59. Jiang, H.L.; Kim, Y.K.; Arote, R.; Nah, J.W.; Cho, M.H.; Choi, Y.J.; Akaike, T.; Cho, C.S. Chitosan-graft-polyethylenimine as a gene carrier. J. Control. Release 2007, 117, 273-280. [CrossRef]

60. Lu, B.; Xu, X.D.; Zhang, X.Z.; Cheng, S.X.; Zhuo, R.X. Low molecular weight polyethylenimine grafted n-maleated chitosan for gene delivery: Properties and in vitro transfection studies. Biomacromolecules 2008, 9, 2594-2600. [CrossRef]

61. Jiang, H.L.; Kim, Y.K.; Arote, R.; Jere, D.; Quan, J.S.; Yu, J.H.; Choi, Y.J.; Nah, J.W.; Cho, M.H.; Cho, C.S. Mannosylated chitosan-graft-polyethylenimine as a gene carrier for raw 264.7 cell targeting. Int. J. Pharm. 2009, 375, 133-139. [CrossRef]

62. Chen, J.; Gao, X.; Hu, K.; Pang, Z.; Cai, J.; Li, J.; Wu, H.; Jiang, X. Galactose-poly(ethylene glycol)-polyethylenimine for improved lung gene transfer. Biochem. Biophys. Res. Commun. 2008, 375, 378-383. [CrossRef]

63. Zhang, Z.; Yang, C.; Duan, Y.; Wang, Y.; Liu, J.; Wang, L.; Kong, D. Poly(ethylene glycol) analogs grafted with low molecular weight poly (ethylene imine) as non-viral gene vectors. Acta Biomater. 2010, 6, 2650-2657. [CrossRef] [PubMed]

64. Chai, Z.; Zhang, X.; Dobbins, A.L.; Rigsbee, K.M.; Wang, B.; Samulski, R.J.; Li, C. Optimization of dexamethasone administration for maintaining global transduction efficacy of adeno-associated virus serotype 9. Hum. Gene Ther. 2019, 30, 829-840. [CrossRef] [PubMed]

65. Seregin, S.S.; Appledorn, D.M.; McBride, A.J.; Schuldt, N.J.; Aldhamen, Y.A.; Voss, T.; Wei, J.; Bujold, M.; Nance, W.; Godbehere, S.; et al. Transient pretreatment with glucocorticoid ablates innate toxicity of systemically delivered adenoviral vectors without reducing efficacy. Mol. Ther. 2009, 17, 685-696. [CrossRef] [PubMed]

66. Suhr, O.B.; Coelho, T.; Buades, J.; Pouget, J.; Conceicao, I.; Berk, J.; Schmidt, H.; Waddington-Cruz, M.; Campistol, J.M.; Bettencourt, B.R.; et al. Efficacy and safety of patisiran for familial amyloidotic polyneuropathy: A phase II multi-dose study. Orphanet J. Rare Dis. 2015, 10, 109. [CrossRef]

67. Nair, N.; Rincon, M.Y.; Evens, H.; Sarcar, S.; Dastidar, S.; Samara-Kuko, E.; Ghandeharian, O.; Viecelli, H.M.; Thöny, B.; De Bleser, P.; et al. Computationally designed liver-specific transcriptional modules and hyperactive factor ix improve hepatic gene therapy. Blood 2014, 123, 3195-3199. [CrossRef]

68. Viecelli, H.M.; Harbottle, R.P.; Wong, S.P.; Schlegel, A.; Chuah, M.K.; Vandendriessche, T.; Harding, C.O.; Thöny, B. Treatment of phenylketonuria using minicircle-based naked-DNA gene transfer to murine liver. Hepatology 2014, 60, 1035-1043. [CrossRef] 
69. Grisch-Chan, H.M.; Schlegel, A.; Scherer, T.; Allegri, G.; Heidelberger, R.; Tsikrika, P.; Schmeer, M.; Schleef, M.; Harding, C.O.; Häberle, J.; et al. Low-dose gene therapy for murine PKU using episomal naked DNA vectors expressing PAH from its endogenous liver promoter. Mol. Ther. Nucleic Acids 2017, 7, 339-349. [CrossRef]

70. Dai, H.; Jiang, X.; Tan, G.C.Y.; Chen, Y.; Torbenson, M.; Leong, K.W.; Mao, H.Q. Chitosan-DNA nanoparticles delivered by intrabiliary infusion enhance liver-targeted gene delivery. Int. J. Nanomed. 2006, 1, 507-522. [CrossRef]

71. Jiang, X.; Dai, H.; Ke, C.Y.; Mo, X.; Torbenson, M.S.; Li, Z.; Mao, H.Q. PEG-b-PPA/DNA micelles improve transgene expression in rat liver through intrabiliary infusion. J. Control. Release 2007, 122, 297-304. [CrossRef] [PubMed]

72. Allan, C.; Burel, J.M.; Moore, J.; Blackburn, C.; Linkert, M.; Loynton, S.; MacDonald, D.; Moore, W.J.; Neves, C.; Patterson, A.; et al. OMERO: Flexible, model-driven data management for experimental biology. Nat. Methods. 2012, 9, $245-253$. [CrossRef] [PubMed]

73. Berntsen, N.L.; Fosby, B.; Valestrand, L.; Tan, C.; Reims, H.M.; Schrumpf, E.; Karlsen, T.H.; Line, P.D.; Melum, E. Establishment of a surgical bile duct injection technique giving direct access to the bile ducts for studies of the murine biliary tree. Am. J. Physiol. Gastrointest. Liver Physiol. 2018, 314, G349-G359. [CrossRef] [PubMed] 